\title{
The influence of diet on anti-cancer immune responsiveness
}

\author{
Laura Soldati ${ }^{*+}{ }^{*}$, Laura Di Renzo ${ }^{2 \dagger}$, Emilio Jirillo ${ }^{3}$, Paolo A. Ascierto ${ }^{4}$, Francesco M. Marincola ${ }^{5}$ \\ and Antonino De Lorenzo ${ }^{2}$
}

\begin{abstract}
Immunotherapy has matured into standard treatment for several cancers, but much remains to be done to extend the reach of its effectiveness particularly to cancers that are resistant within each indication. This review proposes that nutrition can affect and potentially enhance the immune response against cancer. The general mechanisms that link nutritional principles to immune function and may influence the effectiveness of anticancer immunotherapy are examined. This represents also the premise for a research project aimed at identifying the best diet for immunotherapy enhancement against tumours (D.I.E.T project). Particular attention is turned to the gut microbiota and the impact of its composition on the immune system. Also, the dietary patterns effecting immune function are discussed including the value of adhering to a healthy diets such as the Mediterranean, Veg, Japanese, or a Microbiota-regulating diet, the very low ketogenic diet, which have been demonstrated to lower the risk of developing several cancers and reduce the mortality associated with them. Finally, supplements, as omega-3 and polyphenols, are discussed as potential approaches that could benefit healthy dietary and lifestyle habits in the context of immunotherapy.
\end{abstract}

Keywords: Immunotherapy, Healthy diet, Cancer, Microbiome, Functional supplements

\section{Immunotherapy: today's status and future outlook} Check point inhibitor therapy has brought a paradigm shift in the treatment of advanced cancer by introducing immunotherapy as a recognized first and second line modality. The major benefit is the long-term effectiveness, that can be observed with immunotherapy agents compared to other standard therapies such as chemotherapy or pathway inhibitors. However, only a subset of cancers within each indication responds to this treatment leaving the majority of patients unaffected by this potentially curative modality [1].

We have recently shown, that human cancers evolve following a strict selection bottleneck according to a degenerate process based on genetic instability and leading to a trial and error enhancement of oncogenic processes or through an orderly stepwise accumulation of relevant driver mutations. In the former case, the

\footnotetext{
*Correspondence: laura.soldati@unimi.it

${ }^{\dagger}$ Laura Soldati and Laura Di Renzo contributed equally to this work

1 Department of Health Sciences, Università degli Studi di Milano, Via A di

Rudinì 8, 20124 Milan, Italy

Full list of author information is available at the end of the article
}

degenerate and chaotic process associated with enhanced immunogenicity of cancer cells, while in the latter cancer cells adapted to grow without being recognized by the host immune surveillance [2]. Immunotherapy works only in the context of the immunogenic disorderly cancers while silent tumours are resistant. Within immunogenic tumours, only a subset responds to immunotherapy and the reasons for the unpredictable outcomes remain unknown.

Three categories of factors may determine immune responsiveness in cancer: the genetic make up of the host, the somatic profile of cancer cells and the environment [3].

While most efforts to understand immune responsiveness revolve around the somatic alterations of cancer cells and their effect on the host cells within the cancer microenvironment and in the circulation, relatively little information is available about the role played by environmental factors in modulating cancer-interactions. Here, we summarized how a fundamental aspect of daily life, dietary habits, could influence cancer growth and/or responsiveness to immune modulation. Clear variations 
are seeing in the functions of the human immunome according to simple variables such as age, physiological or pathological status as recently discussed by Davis et al. [4].

Several conditions have been associated with variations in immune function. However, nutri-genomics (the analysis of transcriptional programs activated by nutrients) has been championed by few. There are several ways in which nutrition can affect cancer growth through systemic or local effects within the tumour microenvironment (TME). Metabolic factors like the decrease of arginine and tryptophan level, the increased metabolism of glucose with the subsequent increase of lactate levels, and the adenosine pathway, are all well known to have an impact on the immune activity inside the TME. It is also clear that the general metabolic status determining deviations from ideal body weight highly influences the immune status. In addition, particular dietary components such as vitamins may be modulated by the nutritional status and secondarily affect immune function. Moreover, nutrition may affect the gut microbiome, which in turn has drastically different effects on immune function according to its composition [5-7]. All these aspects of nutrition within the context of the immune biology of cancer will be discussed here.

\section{The link between immunity and nutrition}

Food represents not only a source of nutrients for body growth and for the maintenance of essential functions, but also includes dietary components that behave as antigens. Especially, innate and adaptive intestinal immune cells scattered throughout the lamina propria or present within secondary lymphoid organs, such as Peyer's patches and colonic lymphoid follicles, can elicit a robust response when stimulated by food antigens. In fact, it has been demonstrated that food ingestion leads to a condition of post-prandial low-grade inflammation, which is not only regional but also systemic [8]. In healthy volunteers serum levels of the inflammatory cytokine, interleukin (IL)-17, dramatically increases $1 \mathrm{~h}$ after the ingestion of a western-type hyper caloric breakfast [9]. This was not observed in a control group of individuals who ingested along with breakfast polyphenols containing fruit juice. These substances are characterized by a remarkable antiinflammatory activity, which accounts for the reduction of IL-17 serum concentration.

A trial conducted in normal weight children, who followed a Mediterranean diet (MD) for 1 year compared to age matched controls, who disregarded health food recommendations, demonstrated different immune profiles $[10,11]$. Quite interestingly, at the end of the trial in the former group, salivary levels of the anti-inflammatory cytokine, IL-10, increased, while levels of IL-17 decreased. In the latter group of children, who mostly ate "junk food", a dramatic increase in IL-17 was observed at the expense of IL-10. In this context, IL-10 is a cytokine predominantly produced by FOXP3 $+\mathrm{T}$ regulatory (TREG) cells, which are induced in the intestine by several dietary components, such as vitamins (A and D), polyunsaturated fatty acids (omega-3) and polyphenols.

The homeostatic equilibrium between TREG cells (IL10) and Th17 cells (IL-17) is broken in different clinical settings. Overall, obesity, a diet-related disease, represents a systemic inflammatory condition characterized by an excessive production of IL-17 and IL-21, which, in turn, are strong inducers of Th17 cells $[12,13]$. The intense and prolonged inflammatory status in obese people is responsible for diabetes, cardiovascular events, neuro-degeneration, and, in some cases, cancer.

Immunosenescence is known as the decline of the immune system with age accounting for increased frequency of infectious, autoimmune and neoplastic diseases in elderly [14]. Hypo-nutrition in aging aggravates the already impaired immunity, since aged people are frequently malnourished in relation to poor socio-economic conditions, mental illnesses and tooth loss [15]. Importantly, lack of proteins and oligo-elements in elderly determines severe immune deficit, which can be fatal. For instance, zinc deficit in elderly is very common, but undiagnosed, thus leading to $\mathrm{T}$ cell malfunction and increased frequency of respiratory infections and poor responses to vaccination [16]. Consequently, zinc supplementation in the elderly with zinc deficiency is very effective for the treatment of chronic diseases [17]. Among other natural products, evidence suggests that administration of red grape polyphenols to aged people restores impaired $\mathrm{T}$ cell functions, thus increasing protection against winter infections [18]. Moreover, prebiotics, probiotics and symbiotics have been shown to restore innate and adaptive immunity in elderly, also correcting alterations of intestinal microbiota which, under normal conditions, contributes to immune homeostasis, balancing the equilibrium between TREG cells and Th17 cells [19]. The immunomodulation exerted by natural products in elderly is illustrated in Table 1.

Immune cells originating from the circulation including monocytes represent a significant component of the tumour microenvironment [20]. Monocytes differentiate into tumour-associated macrophages (TAMs), whose density positively correlates with tumour progression [20]. In highly immunogenic tumours, $\mathrm{T}$ cytotoxic (Tc) cells are also present, thus leading to tumour destruction or at least limitation of cancer growth. However, tumour cells and TAMs produce suppressive cytokines [for example, IL-10 and transforming growth factor (TGF)-beta], which, in turn, dampen $\mathrm{T}$ cell-mediated cytotoxicity [21]. 


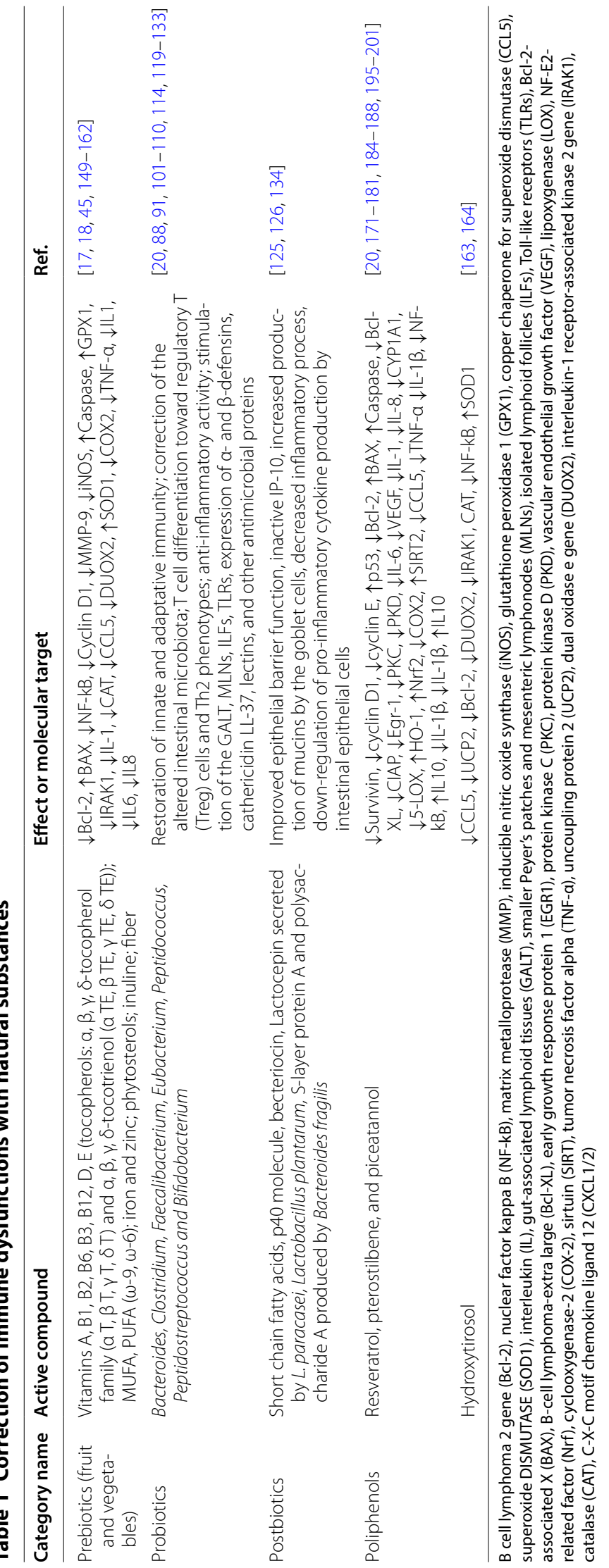


Furthermore, TAMs express PD-1 ligand, which binds to PD-1 inhibiting Tc cell function [22]. Importantly, TAMs secrete the chemokines CCL17 and CCL22, which attract TREG cells, and Th2 cells to tumour site, thus downregulating Th1 cell function [20]. It is well known that Th1-related cytokines, such as IL-2 and interferon (IFN)gamma, allow Tc and natural killer (NK) cells to proliferate, while enhancing their function, respectively. Then, the integrity of the Th1 function is essential for Tc and NK cell-mediated tumour destruction to occur.

In a recent review, Mattner and Wirtz [23] pointed out the ambiguous role of innate lymphoid cells (ILCs) in the tumour development. Th1-type ILCs (ILC1) producing IFN-gamma and Tumour Necrosis Factor (TNF)-alpha play a predominant anti-carcinogenic activity. Th2-type ILCs (ILC2) are both pro-tumorigenic (inhibition of Th1 cells) and anti-tumorigenic (attraction of eosinophils which are cytotoxic to tumour cells). Also the role of Th17-type ILCs (ILC3) is ambiguous, since production of IL-17 and IL-22 favour tumour growth on one side, while, they may also interact with tumour cells via natural cytotoxic receptors or by forming tertiary lymphoid structure that results in cancer cell elimination. It is worth mentioning that the IL-17/IL-22 innate axis in the gut can be modulated by both polyphenols and probiotics, suggesting the potential of dietary manipulation in different clinical settings [24]. However, the exact role of ILCs in the context of cancer has to be better clarified.

The cellular composition of the tumour microenvironment leads to a status of chronic non-resolving inflammation. In fact, TAMs, as well as cancer cells, produce an array of pro-inflammatory cytokines, such as IL-1 beta, TNF-alpha and IL-6 via activation of the transcription factors NF-kB and STAT 3 [25]. In addition, release of reactive oxygen and nitrogen species (ROS, RNS) accounts for epigenetic modifications, arrest of DNA repair mechanisms and DNA mutations, which favour cancer proliferation [26]. Once established, chronic inflammation leads to fibroblast recruitment contributing to the tumour microenvironment and tissue remodelling [27]. For instance, in both hepatocellular carcinoma and pancreatic cancer fibroblasts have been shown to enhance the aggressiveness and invasiveness of tumour cells $[28,29]$. Production of TGF-beta by TAMs leads to accumulation of M2-type macrophages that contribute to fibrosis and hypoxia [30]. Moreover, macrophages produce matrix metalloproteinases, which are enzymes able to degrade the extracellular matrix, thus facilitating metastatic dissemination of cancer cells.

In general terms, TAMs exert procarcinogenic effects, either generating growth factors (Epidermal Growth Factor, Fibroblast Growth Factor and Vascular Endothelial Growth Factor) [31, 32] or releasing cytokines, such as IL-6, which exhibit anti-apoptotic activities on cancer cells [33]. It is should be emphasized, however, the immune infiltrates within the tumour microenvironment are characterized by a natural plasticity and their functional orientation can be reverted by variation in the intra-tumour homeostasis induced by various exogenous agents such as immunotherapy or environmentally related factors such as co-morbidities, diet and microbiota [34, 35].

In conclusion, it is likely that an appropriate dietary regimen can maintain the equilibrium between the inflammatory pathway (triggered by Th17 cells) and the anti-inflammatory cascade of events mainly based on TREG activity. Thus, a nutritional intervention in patients with cancer, should take into account a possible imbalance in the ratio between Th17 and TREG cell function. Accordingly, dietary intake of bioactive principles with food or via the products derived from food with extra health benefits in addition to basic nutritional value, the so called nutraceuticals, should be evaluated in order to enhance anti-tumour immune response.

\section{Dietary patterns that affect immune function: Mediterranean diet, Veg diet, Japanese diet, or a Microbiota stimulating diet}

It is in general appreciated that only long-term and consistent dietary pattern can benefit human health, or conversely, induce inflammation and increased oxidative stress if an unhealthy diet is followed, that leads to chronic disease [36].

The use of specific nutraceutics, discussed in the following paragraphs, should be framed in the broader context of the composite diet.

In this section, we will review some diet patterns that have been assessed for health benefits. We will give the historical background, and review their components.

The diet that affects our health starts from the prenatal stage and accompanies us, with major fluctuations, for the rest of our lives. Here, we will focus on diet appropriate to the adult stage of life.

\section{Mediterranean diet}

The description of the MD stems from the nutritionist Ancel Keys, who in 1945, in the wake of the US Fifth Army, landed in Southern Italy, where he observed one of the highest concentrations of centenarians in the world. He also noticed that cardiovascular diseases, widespread in the USA, were less frequent there. In particular, among the Southern Italians, the prevalence of "wellness" diseases such as hypertension and diabetes mellitus was particularly low [37, 38]. Keys, focused his attention on fat consumption suggesting that the main factor responsible for the observations was the type of 
diet traditionally consumed among people facing the Mediterranean Sea, low in animal fat, as opposed to the Anglo-Saxon diet. The link between serum cholesterol and coronary heart disease mortality was subsequently demonstrated by the Seven Countries Study [39, 40]. Later, the concept of MD was extended to a diet rich in fruits, vegetables, legumes, whole grains, fish and olive oil as the main source of lipid, shared among people living in Spain, Greece, Southern Italy and other Countries facing the Mediterranean basin [41].

A meta-analysis of twelve primary prevention studies, including a total of over a million and a half individuals followed for a period of time varying from 3 to 18 years, found a significant reduction in the risk of overall mortality and mortality due to cardiovascular disease. In addition, it was observed a reduced incidence and mortality of cancer, Parkinson's and Alzheimer's disease, in association with the adherence to a MD [42]. In 2010, the United Nations Educational, Scientific and Cultural Organization (UNESCO) recognized the MD as an "Intangible Cultural Heritage of Humanity".

Recently, Dehghan et al. [43] published in the Prospective Urban Rural Epidemiology (PURE) study that high carbohydrate intake is associated with an increased risk of overall mortality, but not with the risk of cardiovascular disease or cardiovascular mortality. The intake of any type of fat has been associated with a lower risk of overall mortality. In the meantime, the PURE group reported in another article that the assumption of raw fruits, legumes and vegetables, as source of carbohydrates, is associated with lower mortality [44]. For greater clarity and in order to ensure a healthy diet it is important to consider the nutritional quality indexes, and the amount of bioactive food components that bear a potential preventive effect on cancer, as those in MD [45]. The healthy MD is made of a proper combination of quality foods, evaluated both on the basis of the macro and micronutrient content, but also on the absence of contaminating substances such as pesticides, fertilizers and endocrine disrupters, which can alter the intestinal microbiota $[10,46,47]$.

According to current understanding, the key factors against immune-mediated inflammatory responses, such as those occurring in cancer, as well as their potential clinical application, are on one side low cholesterol levels and on the other high levels of antioxidants contained in fruits and vegetables and mono unsaturated fatty acid (MUFA) present in fish, nuts and olive oil.

Moreover, nutritional supplementation with arginine, omega-3 fatty acids and nucleotides results in a marked improvement of immune functions in cancer patients undergoing surgery and a reduction in infectious complications, hospital stay and co-morbidities [48].
New insights into the effects of MD on incidence and mortality of different types of cancer have come from a recent systematic review and meta-analysis that analysed 56 observational studies including 1,784,404 subjects [49]. The results confirmed an inverse association between the adherence to MD and overall cancer-related mortality with risk of developing several types of cancer including: breast, colorectal, gastric, prostate, liver, head and neck, pancreatic and lung cancer.

Among components of the MD, olive oil has been the subject of several epidemiological studies suggesting its protective role in cancer. Associations between increased consumption of olive oil and decreased risk of developing breast [50-53] and colorectal cancer have been observed [54-56]. The main protective effects of olive oil consumption are attributable to the presence of monounsatured fatty acids (MUFA) and phenolic compound, including simple phenols, aldehydic secoiridoids, flavonoids and lignans, although at present there is no scientific evidence determining the role played on the immune system by antioxidant or MUFA components. Oleic acid is the prevalent fatty acid, linoleic and palmitic acids are also present although in minor quantity, while antioxidants include, among others, phenols, lignans and flavonoids $[57,58]$. A systematic review and meta-analysis of 13,800 cancer patients and 23,340 controls in 19 observational studies found an inverse relationship between olive oil consumption and the prevalence of breast of digestive system cancers [59]. Contradictory results were observed between intake of olive oil or its components and prevalence or mortality for prostate cancer [60-63].

\section{Vegetarian diet}

The vegetarian diet includes various dietary patterns that have as common basis the abstinence from the meat and fish. The choice of vegetarianism in ancient times depended mostly on religious choices and it was first discussed in the cultures of ancient Greece and India [64]. In Western Countries, where meat and poultry are the base of protein intake, it is becoming increasingly popular in recent times, both for ethical reasons, against intensive farming and the pollution caused by large animals' flatulence, and health reasons related to the carcinogenicity of red and processed meat [65]. From a theoretical point of view, a diet rich in antioxidants, fibres, monounsaturated and polyunsaturated fatty acids, should decrease cancer incidence and mortality. However, scientific evidence about the anti-cancer effect of vegetarianism remains scarce compared with the data available for MD and the results are complicated to explain.

A meta-analysis of nine studies conducted on 686,629 individuals with breast $(\mathrm{n}=3441)$, colorectal $(\mathrm{n}=4062)$ or prostate $(n=1932)$ cancer did not find any association 
between vegetarian compared to a non-vegetarian diet. Instead, an association was found between colorectal cancer and a semi-vegetarian diet, defined as a low consumption of meat (more than once per month but less than once per week) and also with a pesco-vegetarian diet, defined as consumption of fish more than once per month [66]. From these results, it appears that there is a high heterogeneity among dietary patterns defined as vegetarianism, which may confuses the analysis. Among them, some are considered healthy because they come close to the guidelines focusing on reducing non-communicable diseases [67-71] while others deviate from them. Strict vegans, who exclude from their diet all animal products, including eggs, dairy and honey, undergo deficiencies of vitamin B12, zinc, iron and $\mathrm{n}-3$ poly unsaturated fatty acids (PUFA) [72], while controversial is the deficiency of vitamin $\mathrm{D}$, which depends not only from the intake mainly from fish and seafood, but also from exposure to sunlight and skin tone [73, 74]. In this and other type of vegetarianism, including raw veganism and fruitarianism, supplements of these elements are necessary to avoid serious health problems.

Despite these limitations, a systematic review and meta-analysis including 86 cross-sectional and ten cohort prospective studies about vegetarian and vegan diets, found a significant association with incidence of cancer $(-8 \%)$. However, the number of studies taken in account was limited: 2 cross-sectional and 3 prospective studies for a total of 38,053 patients. Moreover, no significant reduction was observed for breast, colorectal, prostate and lung cancer in comparison to omnivores [75]. These most recent results, cannot, be considered definitive, both for the limited number of studies and subjects, and because do not take into account the duration of the vegetarian or vegan diet, which is undoubtedly an important element. Moreover, also individual defined as omnivores include great variability in type, frequency and amount of meat consumed.

\section{Japanese diet}

Japanese people have the greatest life expectancy and their diet is considered one of the healthiest in the world, low in cholesterol and in caloric intake [76]. But the strengths of this diet may depend on other components. Characteristic among Japanese diet is the wide consumption of green tea, rich in flavonoids, which are phytochemicals with antioxidant and anticancer properties [77]. Moreover, high consumption of vegetables, and among them miso soup, containing wakame (Undaria pinnatifida), a healthy sea vegetable, rich in fucoxanthin, a carotenoid has great antioxidant and anticancer activity [78]. The main source of proteins is fish, especially salmon and tuna fish, sources of also n-3 PUFA. These fatty acids seem to play a critical role in affecting the incidence and growth of colorectal cancer [79], breast cancer treatment efficacy [80], and prevention of prostate cancer [81]. Another common protein source consists of the high intake of soybean products such as tofu. A large body of literature demonstrated anticancer effects of soy and its components: proteins, isoflavones and saponins in in vitro and epidemiological studies [82-85]. In conclusion, similar for the studies in western populations, in which the quality of diet is linked to a lower mortality for chronic diseases including cancer, adherence to Japanese diet is associated to similar outcomes [76].

\section{Very low calorie and ketogenic diets}

Diets restricted in calories are recognized as a sound therapeutic strategy to reduce the risk of chronic diseases, including cancer, and increase life expectancy [86]. Aside caloric restriction, low protein consumption can impair tumour genesis and inflammation [87]. The effect of short-term starvation is related to the decrease of serum levels of glucose and insulin growth factor (IGF), which exerts a potent tumorigenic effect on a variety of cancer cells by promoting proliferation and inhibiting apoptosis [88].

Lately, several studies have demonstrated positive therapeutic effects of very-low-carbohydrate ketogenic diets (VLCKD) on different diseases [89]. Some findings suggested that VLCKD could delay cancer progression due its composition [89, 90]. Ketogenic diets are poor in carbohydrates (usually less than $50 \mathrm{~g} /$ day) and, consequently, more abundant in lipids and proteins. Under this condition, the human body makes use of other mechanisms to generate energy, producing ketone bodies as it occurs in food deprivation. In the last phase of food deprivation and ketogenic diets, glucose become scarce and fatderived ketone bodies become the most prevalent source of energy, promoting a decrease of reactive oxygen species production and cell growth/proliferation [91, 92].

High glucose blood levels can increase cancer risk since glucose is the energy source for human cell proliferation, including cancerous cells [92]. Reduced glucose and insulin/IGF-1 concentrations are capable to sensitize tumor cells and improve resistance of normal cells [93]. Responsible for insulin signaling, Akt is known to induce resistance to apoptosis, changes in the cancer cells metabolism, reduction of beta-oxidation and increased synthesis of lipid in the cytosol [94].

Therefore, since carbohydrates are well-known to increase either serum glucose and insulin, a personalized VLCKD, composed in its majority by fat rather than protein, could play an important role in the treatment of oncologic patients $[95,96]$, also increasing normal cells protection against chemotherapy, as already observed in 
fasting cycles retarding growth of tumors and sensitizing a range of cancer cell types to chemotherapy [88].

\section{Microbiota influence on diet}

In the course of evolution, several microbial ecosystems developed and created a symbiotic mutualism between host and microbes [97-99].

In humans, there are almost $3 \times 10^{13}$ eukaryotic cells and $3.9 \times 10^{13}$ microorganisms [100], and the microbiota exhibits considerable intra- and inter-personal variations, colonizing different habitats as oral cavity, gut, vagina, respiratory tract and skin. Moreover, bacterial genes encompass together more than 100 times the number of genes in the human genome $[101,102]$.

An example of symbiotic proficiency is observable in the human lower gastrointestinal tract that contains approximately $1 \mathrm{~kg}$ of bacteria, with a total genome (microbiome) 100 times that of the host [103] representing the largest source of non-self-antigens for the human organism [104].

In recent years, it has become clear that the gut microbiota plays an important, if not crucial, role in human's physiology and in the development of chronic diseases, including cancer, in particular in the colorectal carcinoma [105], due to its ability to stimulate immunity as an endocrine organ, able to regulate inflammatory, metabolic, and infectious diseases [101, 102, 106].

It is now clear that the influence of the microbiota on cancer development is dependent on the maintenance of chronic inflammation or upon direct effects on immune cells [107]. In fact, observing a diet that nurtures a healthy gut microbiota is critical to human healthy and macronutrients, fibres and some micronutrients have an impact on it [108].

Firmicutes, Bacteroidetes, Actinobacteria, Proteobacteria and Verrucomicrobia represent the major phyla harbouring our intestine. Most predominant genera are Bacteroides, Clostridium, Faecalibacterium, Eubacterium, Ruminococcus, Peptidococcus, Peptidostreptococcus and Bifidobacterium [109, 110], and it is possible to categorized 3 enterotypes, Bacteroides, Prevotella and Ruminococcus on the basis of the microbiota profile [111-115]. Furthermore, gut microbiota differs in males and females, due to the influence played by androgens [116].

The influence of diet on the microbiota has been extensively studied, both by epidemiological and interventional studies that demonstrated that a switch in diet, from vegetarian to carnivore, results in a change in the composition of the microbiome just after $24 \mathrm{~h}$ [117]. Figure 1 shows the impact of microbiota on the function of the mucosal immune system.
In general, the western diet, that is high in animal protein and saturated fatty acids and low in fibre, increases the abundance of bile-tolerant microorganisms and leads to a decrease of beneficial bacteria, as Bifidobacteria and Eubacteria [118], while potentially unhealthy bacteria, as Bacteroides and Clostridia, increase. High animal protein intake, that is often high in fat, lowers the number of Bifidobacteria favoring Bacteroides and Clostridia compared with people who do not eat meat [119]. A high-saturated fatty acid diet increases anaerobic Enterotypes and Bacteroides [114, 119].

Symbiotic bacteria, through their metabolic function, are able to release essential nutrients, metabolizing indigestible compounds [120]. People consuming polyunsaturated fats possess Ruminococcus in their gut, whereas those consuming high carbohydrate and simple sugars are colonized predominantly by Bacteroides. In the microbiota of obese and overweight people, a reduction of Bifidobacterium was observed, with an increase of Firmicutes (Roseburia spp., Eubacterium rectale, and Ruminococcus bromii), and Proteobacteria, that metabolize dietary plant polysaccharides with a consequent gain in energy availability $[121,122]$. Conversely, vegan and vegetarian diets, rich in fermentable nutrients, induce a microbial flora rich in healthy species [123-125].

\section{The impact of microbiota composition on the immune system}

As reported by Stitaya Sirisinha, "our health and probably also our behaviour and mood depend not only on what we eat or what we do (lifestyle behaviour), but also on what we host" [126].

Researchers focused attention on the relationship between gut microbiota and brain development and function, discovering a bidirectional communication between them, defined a microbiota-gut-brain axis. Recent data highlighted the efficacy of probiotics for prevention and/ or treatment of certain eating behaviour disorders and anxiety [127, 128]. Moreover, microbiota diversity plays a crucial role in the maturation and development and functions of both innate and adaptive immune system, [129, 130]. It seems, that the human genome cannot encode all the information necessary to guarantee our health and that this deficiency is overcome by molecules secreted by the intestinal microbiome (the collective genomes of the microbiota) [129, 131].

The interaction between commensal microbes and immune system is bidirectional, and intestinal bacterial species can impact the function of one another [132] (see Fig. 1).

Microbiota can act on several cell types, as intraepithelial lymphocytes, predominantly dominated by $\mathrm{T}$ cells of the $\gamma \delta$ phenotype, and dendritic cells, and stimulate the 


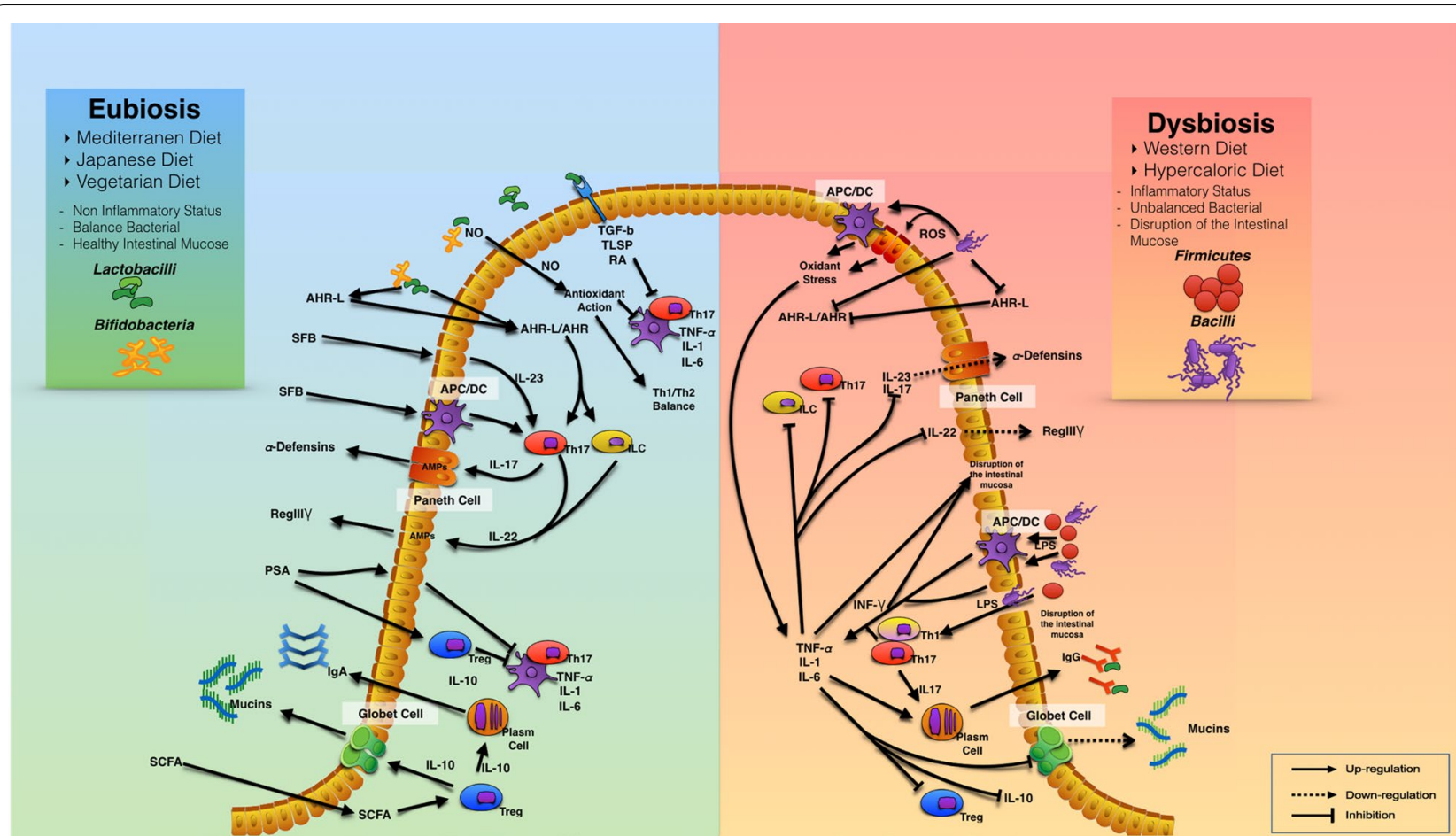

Fig. 1 The role of dietary patterns on microbiota composition and immune system function. Dysbiosis induces cytokines production and NF-kB-mediated local inflammation, promoting tumorigenesis. In the left part of the figure are shown the main mechanisms of interaction between a healthy diet, a balanced gut bacterial flora and the immune system. In the right part are shown alterations of the immune system, intestinal barrier and pathological pathways due to an unhealthy diet and unbalanced gut microbiota

gut-associated lymphoid tissues, smaller Peyer's patches and mesenteric lymphonodes, isolated lymphoid follicles, Toll-like receptors, expression of $\alpha$ - and $\beta$-defensins, cathericidin LL-37, and other antimicrobial proteins. The ultrastructure of the gut is related to microbiota, and intestinal epithelial cells (IECs) can secrete and respond to various cytokines and chemokines and express molecules interacting with lymphocytes [133]. On the other hand, IECs secrete mucins and AMPs that limit microbial interaction with epithelial cells. IECs express CD1d, an MHC-like molecule that presents glycolipids to NK T cells and after the activation of STAT3 produce the antiinflammatory IL-10 [134].

Gram-negative commensal organism Bacteroides thetaiotaomicron, but not the Gram-positive microbe, Bifidobacterium longum, stimulates IECs to produce antimicrobial peptide (AMP), $\alpha$ - and $\beta$-defensins, C-type lectin (e.g., regenerating islet-derived protein, REGIII), cathelicidins, lectins and a number of hydrolytic enzymes [135], and to increase the expression of matrix metalloproteinase (MMP) needed for cleavage of inactive pro-defensins to active defensins [136]. Moreover, Sonnenburg et al. highlighted that $B$. longum can increase the diversity of polysaccharides that can be degraded by B. thetaiotaomicron [137]. Bacteroides thetaiotaomicron down-regulate inflammatory response because interfere with the activation of nuclear factor kappa-light-chainenhancer of activated B cells (NFKB), in the peroxisome proliferator-activated receptor- $\gamma$ (PPAR $\gamma$ )-dependent pathway [138].

Some commensal bacteria can secrete mediators that exert anti-inflammatory activity, as TGF- $\beta$, thymic stromal lymphopoietin, IL-25, IL-33 and IL-10. They also endow DCs and resident macrophages (CX3CR1+) T cell differentiation toward regulatory TREG cells and Th2 phenotypes.

Bacteroides fragilis produced immunosuppressive polysaccharide A that can also function as a TLR2 ligand, thus promoting TREG cell differentiation [139]. Moreover, TREG cell differentiation is observed after production of TGF- $\beta$ due to signal by some species of Clostridium in and after the recognition of $\mathrm{G}$ protein-coupled receptors present on $\mathrm{T}$ cells and IECs by the short chain fatty acids (e.g. butyrate, propionate and acetate) produced as metabolites by microbiota [140]. Tolerogenic DCs produce TGF- $\beta$ and RA that stimulate the development of TREG cells [141].

There is a crosstalk among innate lymphoid cells (ILCs; ILC1, ILC2 and ILC3) located in mucosal epithelium, local immune cells and epithelial cells. ILC2s secrete 
interleukin as IL-4, IL-5, IL-9 and IL-13, and ILC3 s secrete predominantly IL-17 and IL-22 that activate the epithelial and goblet cells to secrete AMPs and mucins able to influence the composition of the microbiota.

Certain components of the inflammasome, such as Nod-like receptor pyrin domain 6 , are selectively expressed by intestinal epithelial cells and can influence the composition of the intestinal microbiota by inducing IL-18 expression [142, 143].

As an immuno-compromised state characterized by pathobiont overgrowth leads to the loss of barrier integrity, hyperinflammation, dysplasia, and tumorigenesis, it is important to develop new strategies for the treatment of diseases associated with low-grade chronic inflammation.

Fusobacterium nucleatum, enterotoxigenic Bacteroides fragilis, and colibactin-producing Escherichia coli generate an inflammatory environment and promote tumorigenesis, such as in colorectal cancer, due to the development of the inflammasome and activation of the NF-кB pathway [144].

However, many of the anti-inflammatory food components, as dietary fibers, omega- 3 fatty acid and some vitamins, tryptophan and tryptophan-derived products, and SCFAs are able to activate the production of anti-inflammatory cytokines (IL-10 and IL-22) through binding to the arylhydrocarbon receptor and the G-protein-coupled receptors [145].

On the other hand, some Lactobacillus strains (L. casei, L. plantarum, L. acidophilus, and L. delbrueckii subsp. bulgaricus) have inhibitory effects on pathogens, due to the modulatory action of TGF $\beta$-expressing T cells, dendritic cells and macrophages, and production of IL-10 $[146,147]$.

Moreover, Bacteroides spp., Lactococcus lactis, Bifidobacterium animalis subsp. Lactis exert and antinflammatory activity, with the production of nitric oxide, shifting the Th1/Th2 balance, and preventing carcinogenesis, through restoration of impaired IL-12 production. They have also direct cytotoxic effects on cancer cells [148, 149].

Interaction between molecules or factors produced by the intestinal probiotics during food metabolism, such as short chain fatty acids, $\mathrm{p} 40$ molecule, bacteriocin, polysaccharide A, could be considered as postbiotics. Postbiotics may be able to act directly or indirectly on the metabolic processes of the host, improving epithelial barrier function. For example, it has been demonstrated that lactocepin produced and secreted by L. paracasei, is able to inactivated CXCL-10, a lymphocyte recruiting chemokine produced by epithelial cells. Lactobacillus plantarum is able to increase production of mucins by the goblet cells. More generally, protein released by probiotics, as S-layer protein A and polysaccharide A are able to decrease inflammatory process, regulating the balance between pro and anti-inflammatory cytokines by DC and T cells [150].

Finally, understanding how to best manipulate the microbiome, controlling therefore the human immune system and its dysregulation, or controlling the effects of postbiotics in the symbiotic status represents an important opportunity to develop new drugs, and combining probiotic supplements, with vaccines and cancer immunotherapies.

\section{Functional supplements}

Dietary natural compounds, also called phytochemicals, can influence cancer risk and tumour behaviour, interfering in all carcinogenic steps, invasion, proangiogenic and the metastatic phase. Therefore, phytochemicals represent a valuable source of effective immune modulators for novel antitumor therapeutic strategies.

Furthermore, advances in nutrigenetics, as individual genetic "make-up" [151-154], and nutrigenomics [155], as the modulation of the whole genome expression induced by food, sustain the crosslink among nutrientsgenes-cancer. Moreover, dietary phytochemicals are recognized to activate or suppress oncogenic noncoding regulatory RNAs network (miRNA), or restore normal expression level of miRNAs with tumour suppressor role [156-158].

Due to the fact that inflammation contributes significantly to the development of chronic non-communicable diseases (CNCD), including cancer $[159,160]$, it is of fundamental importance to select dietary phytochemicals that can modulate expression genes and miRNAs related to inflammasome pathway leading to regulate target immune systems in defined tumor microenvironments.

Inflammation results from an over-reacting immune response and is characterized by the production of different reactive oxygen/nitrogen species and pro-inflammatory mediators including lipid mediators, notably prostaglandins and leukotrienes, and cytokines like TNF-alpha and IL-6, which in turn aggravate inflammation and lead to excessive damage to host tissues [161, 162]. These activate specific patterns of gene expression that in turn act to alter the hormetic mechanisms, i.e. the biphasic dose response phenomenon, characterized by a low dose stimulation and high dose inhibition, that increase cellular stress resistance. This alteration produces tissue degeneration, loss of function of one or more organs, activating oncogene products and/or inactivating tumour-suppressor proteins [161].

Several observational studies have provided scientific evidence that diets rich in fruit, vegetables, legumes, whole grains, fish, low-fat dairy products, and hazelnut, 
reducing the oxidative processes and inflammation $[45,163]$ are associated with lower incidence of $\mathrm{CNCD}$ [164-166]. Moreover, dietary supplementation with antioxidants, including minerals, vitamins and phenolic compounds obtained from plants, exert health benefits, maintaining a desirable pro oxidative/anti-oxidative balance [165-168].

Omega 3, 6 and 9 fatty acid, fat-soluble bioactives with nutraceutical property (tocopherols and phytosterols), vitamins (vitamins B1, B2, B6, niacin, thiamin and $\alpha$-tocopherol, the most active form of vitamin E), essential minerals (selenium, potassium, magnesium, phosphorus, manganese, iron, zinc and copper, and a low level of sodium), essential amino acids, antioxidant phenolics (caffeic acid), dietary fiber (soluble), flavonoids (as catechin, epicatechin, quercetin, procyanidins, phenolic acids (as gallic and protocatechuic acids) can be considered functional foods, that exert physiological benefits beyond basic nutritional function $[45,46,165,166]$.

Because there is a plethora of phytochemicals that appear to be protective against cancer and CNCD, and, in the meantime, there are multiple pathways that may be influenced simultaneously, we have selected some examples of nutraceuticals that act against inflammation and oxidative stress.

Figure 2 shows the dietary impact on immune system.

Vitamin E, a fat-soluble physiological antioxidant belonging to $\alpha, \beta, \gamma, \delta$-tocopherol family $(\alpha \mathrm{T}, \beta \mathrm{T}, \gamma \mathrm{T}$, $\delta \mathrm{T}$ ) and $\alpha, \beta, \gamma, \delta$-tocotrienol ( $\alpha \mathrm{TE}, \beta \mathrm{TE}, \gamma \mathrm{TE}, \delta \mathrm{TE})$ [168] are potent antioxidants with lipoperoxyl radicalscavenging activities. Specific forms of vitamin E, such as $\gamma \mathrm{T}, \delta \mathrm{T}$ and tocotrienols (esp. $\gamma \mathrm{TE}$ ), have anti-inflammatory and antioxidant effects by inducing superoxide dismutase, quinoneoxidoreductase, glutathione peroxidase and by inhibiting cyclooxygenase (COX)-2, signal transducer and activator of transcription-3 (STAT3), nuclear factor kappa-light-chain-enhancer of activated B cells (NF-K B), TNF- $\alpha$, cytokines as interleukin (IL-1, IL-6, IL-8), and inducible nitric oxide synthase [169-178] (see Table 1).

It has been demonstrated that the hydroxytirosol (2-(3,4-dihydroxyphenyl) ethanol, 3,4-DHPEA, HT) has positive effects on antioxidant enzymes activity, against oxidative stress, and DNA damage [179]. Oral administration of gastro-resistant capsules containing $15 \mathrm{mg} /$ day of HT significantly increased antioxidant biomarkers, like thiols groups and total antioxidant status, while

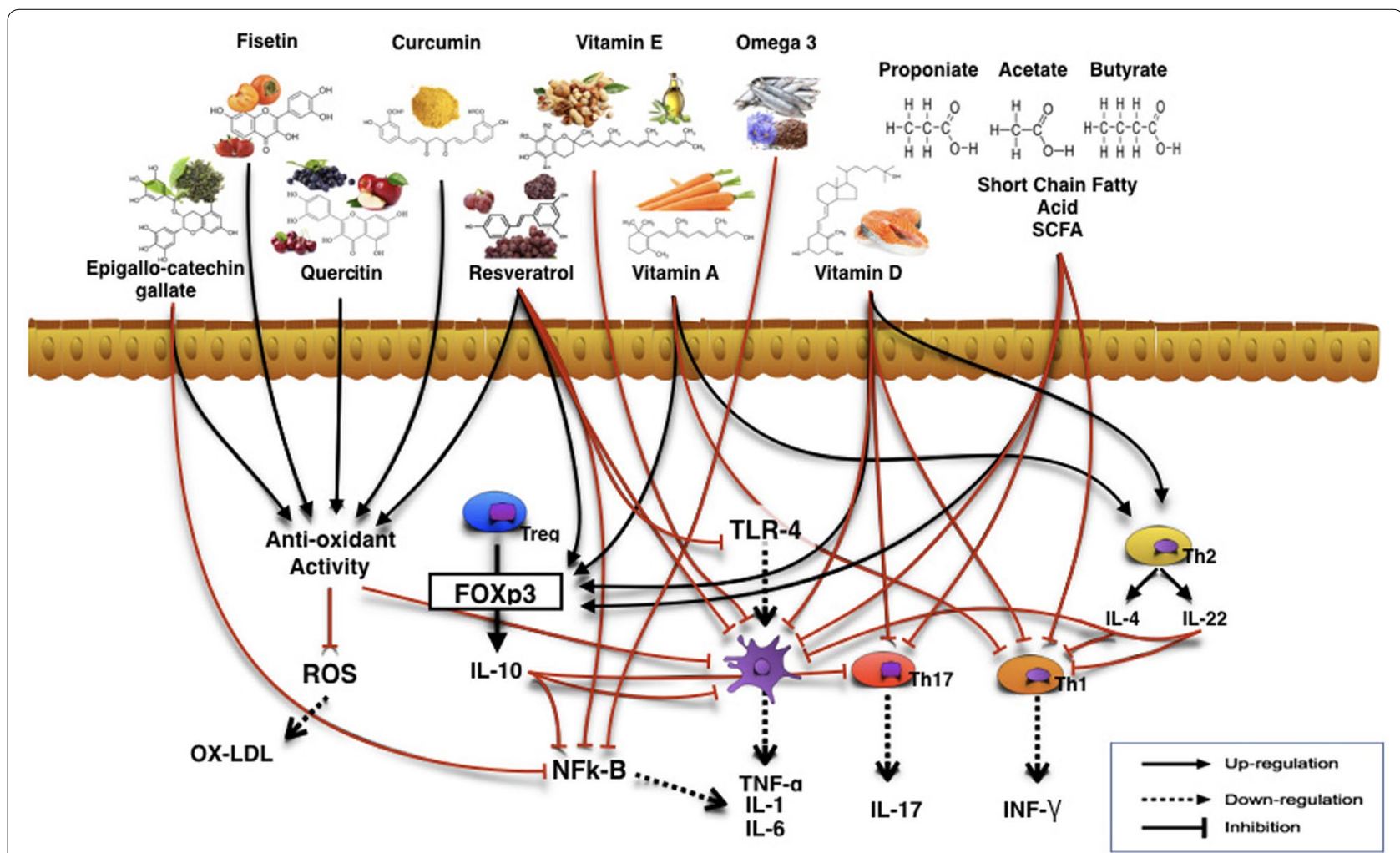

Fig. 2 The benefits of functional nutrients on immune system and inflammation. Role of natural compounds on molecular target to correct immune system alterations, prevent and modulate the onset of cancerous disease 
drastically reduced nitrite and nitrate, malondialdehyde (MDA), and peroxidation of low density lipoprotein cholesterol serum concentrations. These results were related to the significant up-regulation of superoxide dismutase-1 gene expression [180] (see Table 1).

Recently, Bhandari et al. showed that plant extract from Allium wallichii, rich in flavonoids, steroids, glycosides and terpenoids exhibits a good cytotoxicity towards Lymphoma, and moderate cytotoxic activity towards prostate cancer (PC3), cervical cancer (HeLa) and breast cancer (MCF-7) cell lines, and could be an important candidate to be used as an anticancer agent [181].

Epidemiological studies suggest that a higher flavonoid intake is associated with a lower cancer risk [182], affecting all three stages of carcinogenesis (initiation, promotion, and progression) by modulating the signal transduction pathways, controlling cell division and growth, apoptosis, inflammation, angiogenesis, and metastasis. Flavonoid supplementation is therefore considered a promising anticancer therapy [183].

Although food supplies with native forms of phytochemicals can achieve the maximal antitumor effect, clinical effects of these compounds can be reached at high concentrations, impossible to be retrieved from natural sources. Therefore, efforts to synthesize new derivatives are in progress [184].

Considering the complex, often synergistic, beneficial effects of mixtures of bioactive compounds present in a healthy diet, phytochemicals may be a novel adjuvant approach useful in combination with chemotherapeutics for overcoming drug resistance or tumour metastasis in therapy against cancer.

\section{Anti-neoplastic activities exerted by polyphenols}

In the light of the aforementioned concepts, targeting of inflammatory cells or neutralization of pro-inflammatory cytokines in the context of cancer may represent a plausible innovative approach to retard or abrogate tumour growth and influence the effectiveness of anti-cancer immunotherapy. According to large population studies, there is evidence that the daily use of non-steroidal antiinflammatory drugs, such as aspirin to prevent cardiovascular risk, significantly diminished the risk of colorectal and receptor-positive breast cancer [185]. However, the practical limit of this study is the unease of applying this therapeutic approach to healthy people in the absence of cardiovascular risk. On the other hand, use of monoclonal antibodies against pro-inflammatory cytokines (TNF-alpha and IL-6) in different cancers led to sporadic disease stabilization, thus suggesting the poor efficiency of such a therapeutic strategy [20].

With regard to nutritional interventions in cancer, the anti-oxidant and anti-inflammatory properties of polyphenols have been object of intensive investigation. Daily ingestion of polyphenols with fruits, vegetables, cereals, extra virgin olive oil, wine, tea and coffee has also prompted further studies on their anti-cancer activity.

Oolyphenols exhibit broad structural variation in their backbone as well as primary and secondary structures due to differences in methylation, glycosylation and hydroxylation, which result in diverse biological activity [186].

Anti-inflammatory activities displayed by polyphenols, especially flavonoids extracted from red wine or fermented grape marc (FGM), depend on multiple mechanisms.

Resveratrol (3,5,4'-trihydroxystilbene), a naturally occurring polyphenol produced by some plants as a self-defence agent, acts as a phytoalexin, and it is considered to have beneficial effects also on human health. Resveratrol has a wide range of healing and preventive properties, acting as a cardio-protective, neuroprotective and antitumor, antioxidant agent [187]. Furthermore, resveratrol has been shown to induce anti-oxidant enzymes (e.g. glutathione peroxidase, heme-oxygenase, superoxide dismutase) that attenuate oxidative stress [188].

Resveratrol is a potent inhibitor of cyclooxygenase-2 [189], and, therefore, a potent chemo-preventive agent against cancer (prostate, breast, brain, endometrium, rectum, pancreas, skin, lung, ovary and bladder cancer), activating pro-apoptotic signalling molecules while inhibiting anti-apoptotic molecules [190].

In particular, resveratrol is able to activate sirtuins (SIRT), a class of proteins that possesses deacetylase or monoribosyltransferase activity [191]. SIRT acts by deacytylating transcription factors, such as the tumour suppressor $\mathrm{p} 53$, the Forkhead Box proteins family and the transcription factors NF-kB [192, 193]. Di Renzo et al. observed, after the intake of red wine, a higher expression of SIRT2, which was negatively correlated $(\mathrm{P}<0.001)$ with the expression of CCL5 [194].

Red wine polyphenols, when incubated with healthy human monocytes have been shown to interfere with the binding of lipopolysaccharides from gram-negative bacteria to Toll-Like receptor (TLR)-4, likely acting by sterical hindrance [195]. The activation of the transcription factor NF-kB was inhibited, thus leading to a dramatic decrease in pro-inflammatory cytokine production.

Moreover, resveratrol and its analogues pterostilbene (Pter; trans-3,5-dimethoxy-4'-hydroxy-stilbene), and piceatannol (Pic; trans-3,5,3', 4'-tetrahydroxystilbene), regulate miRNAs, causing apoptosis, cell cycle arrest, growth inhibition, inhibition of cell viability, migration, and invasion in various types of cancer: 71 miRNAs are overexpressed in lung cancer cells, 46 miRNAs target 
TGF $\beta$ pathways in colon cancer cell, miR-125b-5p, miR200c-3p, miR-409-3p, miR-122-5p and miR-542-3p are involved in breast cancer cells $[195,196]$.

Curcumin, green tea, polyphenols [epigallo-catechingallate (EPGC)], quercetin and resveratrol are the most effective anti-cancer compounds as they inhibit NF-kB activation [196]. The administration of FGM-derived polyphenols to mice affected by experimental colitis dramatically reduced biomarkers of inflammation such as TNF-alpha and IL-1 beta [197]. Thus, one can hypothesize that polyphenols can impede secretion of cytokines usually released in the tumour microenvironment. Finally, FGM-derived polyphenols activate in vitro peripheral healthy human Foxp3+ TREG cells inducing the production of the anti-inflammatory cytokine IL-10, and polarizing immune responses toward a tolerogenic pathway [198] (see Fig. 2).

From an immunological point of view, polyphenols from blueberry powder were very effective either in vitro or in vivo at inhibiting breast cancer cell proliferation and metastasis, down-regulating IL-6 production [199]. Similarly, curcumin could inhibit the metastatic dissemination of breast cancer, reducing the release of CXCL1/2 [200]. EGCG from green tea induced apoptosis in gamma-irradiated breast cancer cells via inhibition of NF-kB [201]. Xanthohumol, a prenylated flavonoid extracted from hops, when inoculated to nude mice bearing breast cancer xenografts, reduced macrophage infiltrates, increased apoptosis, reduced micro-vessel number and down regulated NF-kB expression [202].

Regulation of ROS by polyphenols is another potential anti-tumour mechanism. Of note, polyphenols are able to scavenge not only ROS but also RNS, peroxynitrous acid, chlorine species and hypochlorous acid by targeting NF-kB and mitogen activated protein kinase-related pathways [203]. Experimentally, Biochanin A, an isoflavonoid extracted from red clover, prevents induction of mammary gland cancer in pre-puberal rats exposed to carcinogenic agents thanks to the reduction of oxidative stress [204]. Resveratrol inhibits 17 beta-estradiolinduced carcinogenesis by up-regulating the expression of nuclear factor erythroid-related factor 2, which has anti-oxidant effects [205]. Similarly, curcumin reduced proliferation of breast cancer cells via nuclear translocation of Nrf-2 [206]. EGCG at low concentrations reduced ROS generation in response to exposure to environmental carcinogens via up regulation of NADPH-quinone oxidoreductase-1, a detoxification enzyme in phase 2 [177]. Conversely, evidence has been provided that polyphenols are also able to exert a pro-oxidant effect, which leads to anti-cancer activity. For instance, in breast cancer cells genistein, a soy isoflavone, generated a pro-oxidant effect via mobilization of copper ions with DNA damage, increase in ROS production and, ultimately, apoptosis [207]. Also, curcumin and EGCG demonstrated pro-oxidant effects in breast cancer cells by increasing ROS generation [208, 209].

Apoptosis of cancer cells is vigorously induced by polyphenols. Quercetin has been shown to induce apoptosis of MCF-7 breast cancer cells binding to the Fas/CD95 receptor via activation of caspase-6 [210]. In addition, quercetin inhibites MDMBA-231 breast cancer cells by activating caspases -3/-8/-9 [211]. Apigenin enhanced apoptosis pathway in SKBR3 breast cancer cells via inhibition of STAT3 [212]. EGCG applied to MD-MB-231 human breast cancer cells led to reduced cell growth and apoptosis related to stimulation of $\mathrm{Bcl}-2$-associated $\mathrm{X}$ protein (BAX), cleavage of poly (ADP-ribose) polymerase protein (PARP) and reduction of Bcl-2 expression [213]. Resveratrol significantly diminished growth of estrogen-positive breast cancer cells inducing apoptosis via reduction of $\mathrm{Bcl} 2 / \mathrm{BAX}$ ratio. Genistein induced apoptosis of MCF-7 cells blocking the activation of Insulin-like Growth Factor receptor and the phosphorylation of protein kinase B (AKT) [214, 215]. Fisetin, a flavonoid present in fruits and vegetables induced apoptosis in MCF-7 cells activating caspases $-7 /-8 /-9$, cleaving PARP, depolarizing mitochondrial membrane, increasing p53 and breaking the plasma membrane in the absence of changes in DNA or phospatidylserine [216].

Autophagy occurs in many cells of the body, even including immune cells and represents a mechanism of protection against starvation, dietary restriction oxidative stress and toxicity. The autophagy process implies catabolic lysosomal degradation, which provides an additional source of energy for the synthesis of new proteins and the maintenance of cellular homeostasis. Autophagy seems to play two main roles in tumour development [217]. Its deficiency has been shown to promote cancer growth, on the one hand. On the other hand, it attenuates necrosis and inflammation in the context of tumour, thus limiting stress-related chromosomal damage. As recently reviewed by Jin and associates [218] autophagy activates innate immune receptors as well as $\mathrm{T}$ and $\mathrm{B}$ lymphocytes for tumour destruction.

Polyphenol-induced autophagy has been considered as a mechanism of tumour cell death. Resveratrolinduced autophagy has been shown to be very effective against cancer growth. This is a type of ROS-triggered autophagy, which occurs via up-regulation of microtubule-associated protein 1 light chain 3-II [219]. Conversely, in human colorectal cancer genetic inhibition of autophagy-related proteins, such as phosphoinositide 3-kinase, lysosome-associated membrane protein $2 \mathrm{~b}$ and Beclin1 abrogated resveratrol-dependent cell death [220]. Quercetin has been shown to induce cytoprotective 
autophagy in gastric cancer cells which was mediated by hypoxia-induced factor 1 alpha and AKT- mammalian target of rapamycin 1 (mTOR) pathways [221]. Modulation of the mTOR signalling occurs via inhibition of the phosphorylation level of the ribosomal S6 subunit through activation of p70S6 kinase and 4e-BP1 [222]. Genistein treatment of ovarian cancer cells led to autophagy via inhibition of AMP-phosphpdiesterase-4A4 and $\mathrm{p} 62 /$ sequestome 1 aggregates activated by extracellular signal-regulated kinases and protein kinase $C$ inhibitors [223].

Curcumin treated cancer cells underwent autophagosome formation and cell death, which was mediated by ROS generation [224]. Similar effects have been observed in ovarian cancer cells and in oral squamous cell carcinoma where besides autophagy curcumin also induced apoptosis inactivating $\mathrm{Bcl}-2$ protein and NF-kB in cancer cells [225].

\section{Conclusions}

The current review highlights the various processes in which nutrient intake could modulate directly or indirectly the immune system and/or the growth of cancer.

Most of the discussion is based on human observation rather than experimental animal models, as the focus of this review was predominantly based on epidemiological grounds. But several experimental models not discussed here extensively substantiate the conclusions.

Yet a gap of knowledge is clear. While the potential mechanisms that may affect immune function and consequently cancer growth and responsiveness to immunotherapy agents have been discovered, very little is known about how they may affect and modulate therapies since parameters linking dietary habits to clinical outcome during immunotherapy are not routinely included.

Here we propose that in the future, detailed information about diet, nutritional status and gut microbiota should be considered in correlative studies during immunotherapy trials identifying parameters that may be relevant to outcome by studying either systemic effects of diet of circulating immune cells, or those that may affect directly the cancer microenvironment. A project is on going to identify the best diets for immunotherapy enhancement against tumours (D.I.E.T project).

\footnotetext{
Abbreviations

AMP: antimicrobial peptide; BAX: BCl-2-associated X protein; $C \mathrm{CL}$ : chemokines; CD1d: cluster of differentiation 1; CNCD: chronic non communicable disease; COX-2: cyclooxygenase-2; DCs: dendritic cells; EPGC: epigallo-catechin-gallate; FGM: fermented grape marc; HT: hydroxytirosol; IEC: intestinal epithelial cell; IFN: interferon; IGF: insulin growth factor; IL: interleukin; ILC: innate lymphoid cell; MD: Mediterranean diet; MDA: malondialdehyde; MHC: major histocompatibility complex; MiRNA: small noncoding regulatory RNA; MMP: metalloproteinase; mTOR: mammalian target of rapamycin 1; MUFA: mono unsaturated
}

fatty acid; NFKB: nuclear factor kappa-light-chain-enhancer of activated B cells; NK: natural killer; n-3: polyunsaturated fatty acids omega-3; Nrf-2: nuclear factor erythroid-derived 2; Ox-LDL: low density lipoproteins oxidation; PARP: poly (ADP-ribose) polymerase protein; PPARY: peroxisome proliferator-activated receptor-ץ; PUFA: poly unsaturated fatty acid; PURE: Prospective Urban Rural Epidemiology; RA: retinoic acid; REGIlly: regenerating islet-derived protein; ROS: reactive oxygen species; RNS: reactive oxygen species; SCFAs: short chain fatty acids; SIRT: sirtuin; STAT3: signal transducer and activator of transcription-3; Th: Thelper cell; TAM: tumour associated macrophage; Tc: T cytotoxic; TGF: transforming growth factor; TLR: Toll-like receptor; TME: tumour micro environment; TNF: Tumour Necrosis Factor; TREG: regulatory T cell; VLCKD: very-low-carbohydrate ketogenic diets.

\section{Authors' contributions}

LS and LDR were responsible for conceiving the ideas. All authors wrote different parts of the manuscript. All authors read and approved the final manuscript.

\section{Author details}

${ }^{1}$ Department of Health Sciences, Università degli Studi di Milano, Via A di Rudinì 8, 20124 Milan, Italy. ${ }^{2}$ Section of Clinical Nutrition and Nutrigenomics, Department of Biomedicine and Prevention, University of Rome Tor Vergata, Via Montpellier 1, 00133 Rome, Italy. ${ }^{3}$ Department of Basic Medical Sciences, Neuroscience and Sensory Organs, University of Bari, 70124 Bari, Italy. ${ }^{4}$ Melanoma, Cancer Immunotherapy and Development Therapeutics Unit, Istituto Nazionale Tumori IRCCS Fondazione "G. Pascale", Via Mariano Semmola snc, 80131 Naples, Italy. ${ }^{5}$ AbbVie Corporation, Redwood City, CA, USA.

\section{Acknowledgements}

The authors thank Dr. Lorenzo Romano for his support in the graphic realization of the figures.

Competing interests

The authors declare that they have no competing interests.

Availability of data and materials

Not applicable.

Consent for publication

Not applicable.

Ethics approval and consent to participate

Not applicable.

Funding

None.

\section{Publisher's Note}

Springer Nature remains neutral with regard to jurisdictional claims in published maps and institutional affiliations.

Received: 5 December 2017 Accepted: 12 March 2018

Published online: 20 March 2018

\section{References}

1. Emens LA, Ascierto PA, Darcy PK, Demaria S, Eggermont AMM, Redmond WL, Seliger B, Marincola FM. Cancer immunotherapy: opportunities and challenges in the rapidly evolving clinical landscape. Eur J Cancer. 2017;81:116-29.

2. Masucci GV, et al. The need for a network to establish and validate predictive biomarkers in cancer immunotherapy. J Transl Med. 2017;15(1):223. https://doi.org/10.1186/s12967-017-1325-2.

3. Wang $E$, Uccellini L, Marincola FM. A genetic inference on cancer immune responsiveness. Oncoimmunology. 2012;1:520-5.

4. Davis MM, Tato CM, Furman D. Systems immunology: just getting started. Nat Immunol. 2017;18:725-32. 
5. Renner K, Singer K, Koehl GE, Geissler EK, Peter K, Siska PJ, Kreutz M. Metabolic hallmarks of tumor and immune cells in the tumor microenvironment. Front Immunol. 2017:8(8):248.

6. De Rosa V, Di Rella F, Di Giacomo A, Matarese G. Regulatory T cells as suppressors of anti-tumor immunity: role of metabolism. Cytokine Growth Factor Rev. 2017;35:15-25.

7. Vijayan D, Young A, Teng MWL, Smyth MJ. Targeting immunosuppressive adenosine in cancer. Nat Rev Cancer. 2017;17(12):709-24.

8. Morabito G, Kucan P, Serafini M. Prevention of postprandial metabolic stress in humans: role of fruit-derived products. Endocr Metab Immune Disord Drug Targets. 2015;15:46-53.

9. Peluso I, Villano DV, Roberts SA, Cesqui E, Raguzzini A, Borges G, Crozier A, Catasta G, Toti E, Serafini M. Consumption of mixed fruit juice drink and vitamin $C$ reduces postprandial stress induced by high fat meal in healthy overweight subjects. Curr Pharm Des. 2014;20:1020-4.

10. Casa R, Sacanella E, Estruch R. The immune protective effect of the Mediterranean diet against chronic low-grade inflammatory disease. Endocr Metab Immune Disord Drug Targets. 2014;14:245-54.

11. Vitale E, Jirillo E, Magrone T. Determination of body mass index and physical activity in normal weight children and evaluation of salivary levels of interleukin 10 and interleukin 17. Clin Immunol Endocr Metab Drugs. 2014;1:81-8.

12. Magrone T, Jirillo E. Chidhood obesity: immune response and nutritional approaches. Front Immunol. 2015;6:76.

13. Magrone T, Jirillo E, Spagnoletta A, Magrone M, Russo MA, Fontana S, Laforgia F, Donvito I, Campanella A, Silvestris F, De Pergola G. Immune profile of obese people and in vitro effects of red grape polyphenols on peripheral blood mononuclear cells. Oxid Med Cell Longev. 2017. https://doi.org/10.1155/2017/9210862.

14. Campisi J. Aging, cellular senescence and cancer. Annu Rev Physiol. 2013;75:685-705.

15. Haase $H$, Rink $L$. The immune system and impact of zinc during aging. Immun Ageing. 2009;6:9.

16. Prasad AS. Discovery of human zinc deficiency: its impact on human health and disease. Adv Nutr. 2013:4:176-90.

17. Mocchegiani E, Costarelli L, Giacconi R, Piacenza F, Basso A, Malavolta R. Zinc, metallothioneins and immunosenescence: effect of zinc supply as nutrigenomic approach. Biogerontology. 2011;12:455-65.

18. Magrone T, Pugliese V, Fontana S, Jirillo E. Human use of leucoselect phytosome with special reference to inflammatory-allergic pathologies in frail elderly patients. Curr Pharm Des. 2014;20:1011-9.

19. Amati L, Marzulli G, Martulli M, Pugliese V, Caruso C, Candore S, Vasto S, Jirillo E. Administration of a synbiotic to free-living elderly and evaluation of cytokines. A pilot study. Curr Pham Des. 2010;16:854-8.

20. Marelli G, Sica A, Vannucci L, Allavena P. Inflammation as target in cancer therapy. Curr Opin Pharmacol. 2017;35:57-65.

21. Coussens LM, Zitvogel L, Palucka AK. Neutralizing tumor promoting chronic inflammation: a magic bullet. Science. 2013;339:286-91.

22. Noman MZ, Desantis G, Janji B, Hasmim M, Karray S, Dessen P, Bronte V, Chouaib S. PD-L1 is a novel direct target of HIF-alpha, and its blockade under hypoxia enhanced MDSC-mediated T cell activation. J Exp Med. 2014;211:781-90.

23. Mattner J, Wirtz S. Friend or foe? The ambiguous role of innate lymphoid cells in cancer. Trends Immunol. 2017;38:29-38.

24. Magrone T, Jirillo E. The interleukin-17/interleukin-22 innate axis in the gut as a new drug target in allergic-inflammatory and autoimmune diseases. A working hypothesis. Endocr Metab Immune Disord Drug Targets. 2014;14:145-51.

25. Mantovani A, Allavena P, Sica A, Balkwill F. Cancer-related inflammation. Nature. 2008:454:436-44.

26. Tudek B, Zdzalik-Bielecka D, Tudek A, Kosicki K, Fabisiewicz A, Speina E. Lipid peroxidation in face of DNA damage, DNA repair and other cellular processes. Free Radic Biol Med. 2017;107:77-89.

27. Cieslik KA, Trial J, Entman ML. Mesenchimal stem cell-derived inflammatory fibroblasts promote monocyte transition into myeloid fibroblasts via an IL-6-dependent mechanism in the aging mouse heart. FASEB J. 2015;241:313-5.

28. Kim GJ, Rhee H, Yoo JE, Ko JE, Lee JS, Kim H, Choi JS, Park YN Increased expression of CCN2, epithelial membrane antigen, and fibroblast activation protein in hepatocellular carcinoma with fibrous stroma showing aggressive behavior. PLoS ONE. 2014;9:e105094.

29. Shan T, Chen S, Chen X, Lin WR, Lin W, Ma J, Wu T, Cui X, Ji H, Li Y, Kang Y. Cancer-associated fibroblasts enhance pancreatic cancer cell invasion by remodeling the metabolic conversion mechanism. Oncol Rep. 2017;37:1971-9.

30. Gong D, Shi W, Yi SJ, Groffen J, Heisterkamp N. TGF-beta signaling plays a critical role in promoting alternative macrophage activation. BMC Immunol. 2012:13:31.

31. Condeelis J, Pollard JW. Macrophages: obligate partners for tumor cell migration, invasion, and metastasis. Cell. 2006;124:263-6.

32. Wyckoff JB, Wand Y, Lin EY, Li JF, Goswami S, Stanley ER, Segall JE, Pollard JW, Condeelis J. Direct visualization of macrophage-assisted tumor cell intravasation in mammary tumors. Cancer Res. 2007;67:2649-56.

33. Liu Y, Li PK, Lin J. Inhibition of STAT 3 signaling blocks the antiapoptotic activity of IL-6 in human liver cancer cells. J Biol Chem. 2010;285:27429-39.

34. Mantovani A, Romero P, Palucka AK, Marincola FM. Tumour immunity: effector response to tumour and role of the microenvironment. Lancet. 2008:371:771-83

35. Lida N, Dzutsev A, Stewart CA, Smith L, Bouladoux N, Weingarten RA, et al. Commensal bacteria control cancer response to therapy by modulating the tumour microenvironment. Science. 2013;342:967-70.

36. Wu S, Powers S, Zhu W, Hannun YA. Substantial contribution of extrinsic risk factors to cancer development. Nature. 2016;529:43-7.

37. Menotti A, Puddu PE, Lanti M, Maiani G, Fidanza F. Cardiovascular risk factors predict survival in middle-aged men during 50 years. Eur J Intern Med. 2013;24:67-74.

38. Menotti A, Alberti-Fidanza A, Fidanza F. The association of the Mediterranean Adequacy Index with fatal coronary events in an Italian middleage male population followed for 40 years. Nutr Metab Cardiovasc Dis. 2012;22:369-75.

39. Keys A, Aravanis C, Blackburn H, Buzina R, Djordjević BS, Dontas AS, Fidanza F, Karvonen MJ, Kimura N, Menotti A, Mohacek I, Nedeljković S, Puddu V, Punsar S, Taylor HL, Van Buchem FSP. Seven countries. A multivariate analysis of death and coronary heart disease. Cambridge: Harvard University Press; 1980.

40. Kromhout D. Serum cholesterol in cross-cultural perspective. The Seven-Countries Study. Acta Cardiol. 1999;54:155-8.

41. Willet WC, Sacks F, Trichopoulou A, Drescher G, Ferro-Luzzi A, Helsing E, et al. Mediterranean diet pyramid: a cultural model for healthy eating. Am J Clin Nutr. 1995:61:1402s-6s.

42. Sofi F, Cesari F, Abbate R, Gensini GF, Casini A. Adherence to Mediterranean diet and health status: meta-analysis. BMJ. 2008;337:a1344.

43. Dehghan M, Mente A, Zhang X, on behalf of the Prospective Urban Rural Epidemiology (PURE) study investigators, et al. Associations of fats and carbohydrate intake with cardiovascular disease and mortality in 18 countries from five continents (PURE): a prospective cohort study. Lancet. 2017:390:2050-62.

44. Miller V, Mente A, Dehghan M, et al. Fruit, vegetable, and legume intake, and cardiovascular disease and deaths in 18 countries (Prospective Urban Rural Epidemiology [PURE]): a prospective cohort study. Lancet. 2017:390:2037-49.

45. Di Daniele N, Noce A, Vidiri MF, Moriconi E, Marrone G, AnnicchiaricoPetruzzelli M, D'Urso G, Tesauro M, Rovella V, De Lorenzo A. Impact of Mediterranean diet on metabolic syndrome, cancer and longevity. Oncotarget. 2017:8:8947-79.

46. De Lorenzo A, Noce A, Bigioni M, Calabrese V, Della Rocca DG, Di Daniele N, Tozzo C, Di Renzo L. The effects of Italian Mediterranean organic diet (IMOD) on health status. Curr Pharm Des. 2010;16:814-24.

47. Di Renzo L, Di Pierro D, Bigioni M, et al. Is antioxidant plasma status in humans a consequence of the antioxidant food content influence? Eur Rev Med Pharmacol Sci. 2007;1 1:185-92.

48. Braga M, Wischmeyer PE, Drover J, Heyland DK. Clinical evidence for pharmaconutrition in major elective surgery. JPEN J Parenter Enteral Nutr. 2013:37(5 Suppl.):66Se72S.

49. Schwingshackl L, Hoffmann G. Adherence to Mediterranean diet and risk of cancer: an update systematic review and systematic meta-analysis of observational studies. Cancer Med. 2015:4:1933-47. 
50. Sieri S, Krog V, Pala V, Muti P, Micheli A, Evangelista A, et al. Dietary patterns and the risk of breast cancer in the ORDET cohort. Cancer Epidemiol Biomark Prev. 2004;13:562-72.

51. Toledo E, Salas-Salvadò J, Donat-Vargas C, Buil-Cosiales P, Estruch R,

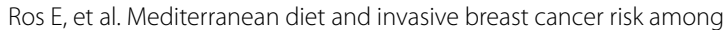
women at high cardiovascular risk in the PREDIMED trial: a randomized Clinical Trial. JAMA Intern Med. 2015:175:1752-60.

52. Trichopoulou A, Bamia C, Lagiou P, Trichopoulos D. Conformity to traditional Mediterranean diet and breast cancer risk in the Greek EPIC (European Prospective Investigation into Cancer and Nutrition). Am J Clin Nutr. 2010;92:620-5.

53. Buckland G, Travier N, Agudo A, Fonseca-Nunes A, Navarro C, Lagiou $P$, et al. Olive oil intake and breast cancer risk in the Mediterranean countries of the European Prospective Investigation into Cancer and Nutrition Study. Int J Cancer. 2012;131:2465-9.

54. Levi F, Pasche C, La Vecchia C, Lucchini F, Franceschi F. Food groups and colorectal cancer risk. Br J Cancer. 1999;79:1283-7.

55. Stoneham M, Goldacre M, Seagroatt V, Gill L. Olive oil, diet and colorectal cancer: an ecological study and a hypothesis. J Epidemiol Commun Health. 2000:54:756-60.

56. Braga C, La Vecchia C, Franceschi S, Negri E, Parpinel M, Decarli A, et al. Olive oil, other seasoning fats, and the risk of colorectal carcinoma. Cancer. 1998;82:448-53.

57. Owen RB, Giacosa H, Hull WE, Haubner R, Spiegelhalder B, Bartsch H. The antioxidant/anticancer potential of phenolic compound isolated from olive oil. Eur J Cancer. 2000;36:1235-47.

58. Owen RB, Giacosa A, Hull WE, Haubner R, Spiegelhalder B, Bartsch H. Olive-oil consumption and health: the possible role of antioxidants. Lancet Oncol. 2000;1:107-12.

59. Psaltopoulou T, Kosti RI, Haidopolous D, Dimopoulos M, Panagiotakos DB. Olive oil intake is inversely related to cancer prevalence: a systematic review and a meta-analysis of 13,800 patients and 23,240 controls in 19 observational studies. Lipids Health Dis. 2011;10:127.

60. De Stefani E, Ronco AL, Deneo-Pellegrini H, Boffetta P, Aune D, Acosta $G$, et al. Dietary patterns and risk of advanced prostate cancer: a principal component analysis in Uruguay. Cancer Causes Control. 2010;21:1009-16.

61. Hodge AM, English DR, McCredie MR, Severi G, Boyle P, Hopper GL, et al. Foods, nutrients and prostate cancer. Cancer Causes Control. 2004:15:11-20.

62. Kim DJ, Gallagher RP, Hislop TG, Holowaty EJ, Howe GR, Jain M, et al. Premorbid diet in relation to survival from prostate cancer. Cancer Causes Control. 2000;11:65-77.

63. Richman EL, Kenfield SA, Chavarro JE, Stampfer MJ, Giovannucci EL, Willett WC, et al. Fat intake after diagnosis and risk of lethal prostate cancer and all-cause mortality. JAMA Intern Med. 2013;173:1318-26.

64. Leitzmann C. Vegetarian nutrition: past, present, future. Am J Clin Nutr. 2014;100:496S-502S.

65. Bouvard V, Loomis D, Guiton KZ, Grosse Y, El Ghissassi F, BenbrahimTallaa $L$, et al. Carcinogenicity of consumption of red and processed meat. Lancet Oncol. 2015;16:1599-600.

66. Godos J, Bella F, Sciacca S, Galvano F, Grosso G. Vegetarianism and breast, colorectal and prostate cancer risk: an overview and metaanalysis of cohort studies. J Hum Nutr Diet. 2017;30:349-59.

67. WHO guidelines on nutrition. Geneva:WHO; 2017. http://www.who.int/ publications/guidelines/nutrition/en/.

68. Dietary guidelines for Americans 2015-2020. Washington: Office of Disease Prevention and Health Promotion; 2015. https://health.gov/ dietaryguidelines/2015/guidelines/. Accessed 16 Dec 2015.

69. Millen BE, Abrams S, Adams-Campbell L, Anderson CA, Brenna JT, Campbel WW, et al. The 2015 dietary guidelines advisory committee scientific report: development and major conclusions. Adv Nutr. 2016;7:438-44.

70. Dietary reference values and dietary guidelines, European Food Safety Authority. Parma. 2017. https://www.efsa.europa.eu/en/topics/topic/ drv.

71. Nordic nutrition recommendations 2012. Copenhagen: Nordic co-operation. 2012. https://www.norden.org/en/theme/nordic-nutrition-recom mendation.

72. Li D. Chemistry behind vegetarianism. J Agric Food Chem. 2011:59:777-84
73. Crowe FL, Steur M, Allen NE, Appleby NL, Travis RC, Key TJ. Plasma concentrations of 25-hydroxyvitamin D in meat eaters, fish eaters, vegetarians and vegans: results from the EPIC-Oxford study. Public Health Nutr. 2011;14:340-6.

74. Chan J, Jaceldo-Siegl K, Fraser GE. Serum 25-hydroxyvitamin D status of vegetarians, partial vegetarians, and non vegetarians; the Adventist Health Study-2. Am J Clin Nutr. 2009;89:1686S-92S.

75. Dinu M, Abbate R, Gensini GF, Casini A, Sofi F. Vegetarian, vegan diets and multiple health outcomes: a systematic review and meta-analysis of observational studies. Crit Rev Food Sci Nutr. 2017;57:3640-9.

76. Kurotani K, Akter S, Kashino I, Goto A, Mizoue T, Noda M, et al. Quality of diet and mortality among Japanese men and women: Japan Public Health Center based prospective study. BMJ. 2016:352:1209.

77. Kerry LI, Majken KJ, Hodgson JM, Eliassen AH, Cassidy A, Rimm EB. Association of flavonoid-rich foods and flavonoids with risk of all-cause mortality. Br J Nutr. 2017;117:1470-7.

78. D'Orazio N, Gemello E, Gammone MA, De Girolamo M, Ficoneri C, Riccioni G. Fucoxantin: a treasure from the sea. Mar Drugs. 2012;10:604-16.

79. Calviello G, Serini S, Piccioni E. n-3 polyunsaturated fatty acids and the prevention of colorectal cancer: molecular mechanism involved. Curr Med Chem. 2007;14:3059-69.

80. Bougnoux P, Hajjaji N, Maheo K, Couet C, Chevalier S. Fatty acids and breast cancer: sensitization to treatments and prevention of metastatic re-growth. Prog Lipid Res. 2010;49:76-86.

81. Gu Z, Suburu J, Chen H, Chen YQ. Mechanisms of omega-3 polyunsaturated fatty acids in prostate cancer prevention. Biomed Res Int. 2013;2013:824563.

82. Lima A, Oliveira J, Saùde F, Mota J, Ferreira RB. Proteins in soy might have a higher role in cancer prevention than previously expected: soybean protein fraction are more effective MMP-9 inhibitors than nonprotein fractions, even in cooked seeds. Nutrients. 2017:9:201.

83. Budhathoki S, Joshi AM, Ohnaka K, Toyomura K, Kono S, Mibu R, et al. Soy food and isoflavone intake and colorectal cancer risk: the Fukuoka Colorectal Cancer study. Scand J Gastroenterol. 2011;46:165-72.

84. Ollberding NJ, Lim U, Wilkens LR, Setiawan VW, Shvetson YB, Henderson $\mathrm{BE}$, et al. Legume, soy, tofu, and isoflavone intake and endometrial cancer risk in postmenopausal women in the multiethnic cohort study. J Cancer Natl Inst. 2012;104:67-76.

85. Nagata C, Mizoue T, Tanaka K, Tsuji I, Tamakoshi A, Matsuo K, et al. Soy intake and breast cancer risk: an evaluation based on a systematic review of epidemiologic evidence among Japanese population. Jpn J Clin Oncol. 2014:44:282-95.

86. Omodei D, Fontana L. Calorie restriction and prevention of age-associated chronic disease. FEBS Lett. 2011;585:1537-42.

87. Peng W, Robertson L, Gallinetti J, Mejia P, Vose S, Charlip A, Chu T, Mitchell JR. Surgical stress resistance induced by single amino acid deprivation requires Gcn2 in mice. Sci Transl Med. 2012;4(118):118ra11. https://doi.org/10.1126/scitranslmed.3002629.

88. Lee C, Raffaghello L, Brandhorst S, Safdie FM, Bianchi G, MartinMontalvo A, Pistoia V, Wei M, Hwang S, Merlino A, Emionite L, de Cabo R, Longo VD. Fasting cycles retard growth of tumors and sensitize a range of cancer cell types to chemotherapy. Sci Transl Med. 2012:4(124):124ra27.

89. Branco AF, Ferreira A, Simões RF, Magalhães-Novais S, Zehowski C, Cope E, Silva AM, Pereira D, Sardão VA, Cunha-Oliveira T. Ketogenic diets: from cancer to mitochondrial diseases and beyond. Eur J Clin Investig. 2016;46(3):285-98. https://doi.org/10.1111/eci.12591.

90. Fine EJ, Segal-Isaacson CJ, Feinman RD, Herszkopf S, Romano MC, Tomuta N, et al. Targeting insulin inhibition as a metabolic therapy in advanced cancer: a pilot safety and feasibility dietary trial in 10 patients. Nutrition. 2012;28:1028-35.

91. Veech RL. The therapeutic implications of ketone bodies: the effects of ketone bodies in pathological conditions: ketosis, ketogenic diet, redox states, insulin resistance, and mitochondrial metabolism. Prostaglandins Leukot Essent Fatty Acids. 2004;70:309-19.

92. Stocks T, Rapp K, Bjorge T, Manjer J, Ulmer H, Selmer R, Lukanova A, Johansen D, Concin H, Tretli S, Hallmans G, Jonsson H, Stattin P. Blood glucose and risk of incident and fatal cancer in the metabolic syndrome and cancer project (me-can): analysis of six prospective cohorts. PLoS Med. 2009;6:e1000201. 
93. Ramsey MM, Ingram RL, Cashion AB, Ng AH, Cline JM, Parlow AF, Sonntag WE. Growth hormone-deficient dwarf animals are resistant to dimethylbenzanthracine (DMBA)-inducedmammary carcinogenesis. Endocrinology. 2002;143:4139-42.

94. Rose DP, Vona-Davis L. The cellular and molecular mechanisms by which insulin influences breast cancer risk and progression. Endocr Relat Cancer. 2012;19:R225-41.

95. Giovannucci E, Harlan DM, Archer MC, Bergenstal RM, Gapstur SM, Habel LA, et al. Diabetes and cancer: a consensus report. CA Cancer J Clin. 2010;60:207-21.

96. Fine EJ, Feinman RD. Thermodynamics of weight loss diets. Nutr Metab. 2004;1:15.

97. Ley RE, Peterson DA, Gordon Jl. Ecological and evolutionary forces shaping microbial diversity in the human intestine. Cell. 2006;124:837-48.

98. Mazmanian SK, Kasper DL. The love-hate relationship between bacterial polysaccharides and the host immune system. Nat Rev Immunol. 2006:6:849-58.

99. Round JL, Mazmanian SK. The gut microbiome shapes intestinal immune responses during health and disease. Nat Rev Immunol. 2009;9:313-23.

100. Sender R, Fuchs S, Milo R. Are we really vastly outnumbered? Revisiting the ratio of bacterial to host cells in humans. Cell. 2016;164:337-40.

101. The Human Microbiome Project Consortium. Structure, function and diversity of the healthy human microbiome. Nature. 2012;486:207-14.

102. Ding T, Schloss PD. Dynamics and associations of microbial community types across the human body. Nature. 2014;509:357-60.

103. Caballero S, Pamer EG. Microbiota-mediated inflammation and antimicrobial defence in the intestine. Annu Rev Immunol. 2015;33:227-56.

104. Sekirov I, Russell SL, Antunes LCM, Finlay BB. Gut microbiota in health and disease. Physiol Rev. 2010;90:859-904.

105. Gagnière J, Raisch J, Veziant J, Barnich N, Bonnet R, Buc E, et al. Gut microbiota imbalance and colorectal cancer. World J Gastroenterol. 2016;22:501-18

106. Cho I, Blaser MJ. The human microbiome at the interface of health and disease. Nat Rev Genet. 2012;13:260-70.

107. David LA, Maurice CF, Carmody RN, Gootomberg DB, Button JE, Wolfe $\mathrm{BE}$, et al. Diet rapidly and reproducibly alters the human gut microbiome. Nature. 2014;505:559-63.

108. Rajagopala SV, Vashee S, Oldfield LM, Venter JC, Telenti A, Nelsen KE. The human microbiome and cancer. Cancer Prev Res. 2017;10:226-34.

109. Jain N, Walker WA. Diet and host-microbial crosstalk in postnata intestinal immune homeostasis. Nat Rev Gastroenterol Hepatol. 2015;12:14-25.

110. Eckburg PB, Bik EM, Bernstein CN, Purdom E, Dethlefsen L, Sargent $M$, et al. Diversity of the human intestinal microbial flora. Science. 2005:308:1635-8.

111. Cresci GA, Bawden E. Gut microbiome: what we do and don't know. Nutr Clin Pract. 2015;30:734-46.

112. Yatsunenko T, Rey FE, Manary MJ, Trehan I, Dominguez-Bello MG, Contreras $\mathrm{M}$, et al. Human gut microbiome viewed across age and geography. Nature. 2012;486:222-7.

113. O'toole PW, Jeffery IB. Gut microbiota and aging. Science. 2015;350:1214.

114. Wu GD, Chen J, Hoffmann C, Bittinger K, Chen YY, Keibaugh SA, et al Linking long-term dietary patterns with gut microbial enterotypes. Science. 2011;334:105-8.

115. Fukuda S, Ohno H. Gut microbiome and metabolic diseases. Semin Immunopathol. 2014;36:103-14.

116. Yurkovetskiy L, Burrows M, Khan AA, Graham L, Volchkov P, Becker L, Antonopoulos D, Umesaki Y, Chervonsky AV. Gender bias in autoimmunity is influenced by microbiota. Immunity. 2013;39:400-12.

117. Singh RK, Chang HW, Yan D, Lee KM, Ucmak D, Wong K, et al. Influence of diet on the gut microbiome and implications for human health. JTM. 2017; 15:73.

118. Thomas S, Izard J, Walsh E, Batich K, Chongsathidkiet P, Clarke G, et al. The host microbiome regulates and maintains human health: a primer and perspective for non-microbiologists. Cancer Res. 2017;77:1783-812.

119. Institute of Medicine of the National Academies. Dietary fats: total fat and fatty acids. In: Dietary reference intakes for energy, carbohydrate, fiber, fat, fatty acids, cholesterol, protein and aminoacids (macronutrients). Washington DC: National Academies Press; 2002. p. $335-442$.

120. Reddy BS, Welsburger JH, Wynder EL. Effects of high risk and low risk diets for colon carcinogenesis on fecal microflora and steroids in man. J Nutr. 1975;105:878-84.

121. Hooper LV, Gordon Jl. Commensal host-bacterial relationships in the gut. Science. 2001;292:1115-8.

122. Wu GD, Compher C, Chen EZ, Smith SA, Shah RD, Bittinger K, et al. Comparative metabolomics in vegans and omnivores reveal constraints on diet-dependent gut microbiota metabolite production. Gut. 2016;65:63-72.

123. Denoth F, Scalese M, Siciliano V, Di Renzo L, De Lorenzo A, Molinaro S. Clustering eating habits: frequent consumption of different dietary patterns among the Italian general population in the association with obesity, physical activity, sociocultural characteristics and psychological factors. Eat Weight Disord. 2016;21:257-68.

124. Aron-Wisnewsky J, Clement K. The gut microbiome, diet, and links to cardiometabolic and chronic disorders. Nat Rev Nephrol. 2016;12:169-81.

125. Xu Z, Knight R. Dietary effects on human gut microbiome diversity. Br J Nutr. 2015;113:S1-5

126. Sirisinha S. The potential impact of gut microbiota on your health: current status and future challenges. Asian Pac J Allergy Immunol. 2016:34:249-64.

127. Di Renzo L, Tyndall E, Gualtieri P, Carboni C, Valente R, Ciani AS, Tonini MG, De Lorenzo A. Association of body composition and eating behavior in the normal weight obese syndrome. Eat Weight Disord. 2016;21:99-106.

128. De Lorenzo A, Costacurta M, Merra G, Gualtieri P, Cioccoloni G, Marchetti M, Varvaras D, Docimo R, Di Renzo L. Can psychobiotics intake modulate psychological profile and body composition of women affected by normal weight obese syndrome and obesity? A double blind randomized clinical trial. J Transl Med. 2017;15:135.

129. Macpherson AJ, Harris NL. Interactions between commensal intestinal bacteria and the immune system. Nat Rev Immunol. 2004;4:478-85.

130. Pickard JM, Chervonsky AV. Intestinal fucose as a mediator of hostmicrobe symbiosis. J Immunol. 2015;194:5588-93.

131. Zaneveld J, et al. Host-bacterial coevolution and the search for new drug targets. Curr Opin Chem Biol. 2008;12:109-14.

132. Sonnenburg JL, Chen CT, Gordon Jl. Genomic and metabolic studies of the impact of probiotics on a model gut symbiont and host. PLoS Biol. 2006:4:e413.

133. Kabat AM, Srinivasam N, Maloy KJ. Modulation of immune development and function by intestinal microbiota. Trends Immunol. 2014;35:507-17.

134. Olszak T, Neves JF, Dowds CM, Baker K, Glickman J, et al. Protective mucosal immunity mediated by epithelial CD1d and IL-10. Nature. 2014;509:497-502.

135. Cash HL, Whitham CV, Behrendt CL, Hooper LV. Symbiotic bacteria direct expression of an intestinal bactericidal lectin. Science. 2006:313:1126-30.

136. Takiishi T, Fenero CIM, Camara NOS. Intestinal barrier and gut microbiota: shaping our immune responses throughout life. Tissue Barriers. 2017;5:e1373208.

137. Fabbiano S, Suarez-Zamorano N, Trajkovski M. Host-microbiota mutualism in metabolic diseases. Front Endocrinol. 2017;8:267.

138. Ong HS, Yim HCH. Microbial factors in inflammatory diseases and cancers. Adv Exp Med Biol. 2017;1024:153-74.

139. De Rosa V, Galgania M, Santopaola M, Colamatteo A, Laccettia R, Matarese G. Nutritional control of immunity: balancing the metabolic requirements with an appropriate immune function. Semin Immunol. 2015;27:300-9.

140. Maynard CL, Elson CO, Hatton RD, Weaver CT. Reciprocal interactions of the intestinal microbiota and immune system. Nature. 2012;489:231-41.

141. Elinav E, Strowig T, Kau AL, Henao-Mejia J, Thaiss CA, et al. NLRP6 inflammasome regulates colonic microbial ecology and risk for colitis. Cell. 2011;145:745-57.

142. Brennan CA, Garrett WS. Gut microbiota, inflammation, and colorectal cancer. Annu Rev Microbiol. 2016;70:395-411.

143. Zhou L. AHR function in lymphocytes: emerging concepts. Trends Immunol. 2016:37:17-31. 
144. Di Giacinto C, Marinaro M, Sanchez M, Strober W, Boirivant M. Probiotics ameliorate recurrent Th1-mediated murine colitis by inducing IL-10 and IL-10-dependent TGF-beta-bearing regulatory cells. J Immunol. 2005; 174:3237-46.

145. Abedin-Do A, Taherian-Esfahani Z, Ghafouri-Fard S, Motevaseli E. Immunomodulatory effects of Lactobacillus strains: emphasis on their effects on cancer cells. Immunotherapy. 2015;7:1307-29.

146. Motevaseli E, Shirzad M, Akrami SM, et al. Normal and tumour cervical cells respond differently to vaginal lactobacilli, independent of $\mathrm{pH}$ and lactate. J Med Microbiol. 2013;62:1065-72.

147. Ballal SA, Veiga P, Fenn K, Michaud M, Kim JH, et al. Host lysozymemediated lysis of Lactococcus lactis facilitates delivery of colitis-attenuating superoxide dismutase to inflamed colons. Proc Natl Acad Sci USA. 2015;112:7803-8

148. Tsilingiri K, Rescigno M. Postbiotics: what else? Benef Microbes. 2013:4:101-7.

149. Grosso G, Marventano S, Yang J, Micek A, Pajak A, Scalfi L, Galvano F, Kales NS. A comprehensive meta-analysis on evidence of Mediterranean diet and cardiovascular disease: are individual components equal? Crit Rev Food Sci Nutr. 2017:57:3218-32.

150. Di Renzo L, Marsella LT, Sarlo F, Soldati L, Gratteri S, Abenavoli L, De Lorenzo A. C677T gene polymorphism of MTHFR and metabolic syndrome: response to dietary intervention. J Transl Med. 2014;12:329.

151. Di Renzo L, Rizzo M, lacopino L, Sarlo F, Domino E, Jacoangeli F, Colica C, Sergi D, De Lorenzo A. Body composition phenotype: Italian Mediterranean diet and C677T MTHFR gene polymorphism interaction. Eur Rev Med Pharmacol Sci. 2013;17:2555-65.

152. Di Renzo L, Gratteri S, Sarlo F, Cabibbo A, Colica C, De Lorenzo A. Individually tailored screening of susceptibility to sarcopenia using p53 codon 72 polymorphism, phenotypes, and conventional risk factors. Dis Markers. 2014;2014:743634.

153. Braicu C, Mehterov N, Vladimirov B, Sarafian V, Nabavi SM, Atanasov AG, Berindan-Neagoe I. Nutrigenomics in cancer: revisiting the effects of natural compounds. Semin Cancer Biol. 2017;46:84-106.

154. Chatterjee A, Rodger EJ, Eccles MR. Epigenetic drivers of tumourigenesis and cancer metastasis. Semin Cancer Biol. 2017. https://doi. org/10.1016/j.semcancer.2017.08.004.

155. Ambros V. MicroRNAs: tiny regulators with great potential. Cell. 2001;107:823-6.

156. Budisan L, Gulei D, Zanoaga OM, Irimie Al, Sergiu C, Braicu C, Gherman CD, Berindan-Neagoe I. Dietary intervention by phytochemicals and their role in modulating coding and non-coding genes in cancer. Int J Mol Sci. 2017;18:1178.

157. De Lorenzo A, Soldati L, Sarlo F, Calvani M, Di Lorenzo N, Di Renzo L. New obesity classification criteria as a tool for bariatric surgery indication. World J Gastroenterol. 2016;22:681-703.

158. Balkwill F, Mantovani A. Inflammation and cancer: back to Virchow? Lancet. 2001;357:539-45.

159. Calabrese V, Cornelius C, Trovato A, Cavallaro M, Mancuso C, Di Renzo L, Condorelli D, De Lorenzo A, Calabrese EJ. The hormetic role of dietary antioxidants in free radical-related diseases. Curr Pharm Des. 2010;16:877-83.

160. Di Renzo L, Galvano F, Orlandi C, Bianchi A, Di Giacomo C, La Fauci L, Acquaviva R, De Lorenzo A. Oxidative stress in normal-weight obese syndrome. Obesity. 2010;18(11):2125-30.

161. Cavallo DN, Horino M, McCarthy WJ. Adult intake of minimally processed fruits and vegetables: associations with cardiometabolic disease risk factors. J Acad Nutr Diet. 2016;116:1387-94.

162. Zamora-Ros R, et al. Dietary intakes and food sources of phenolic acids in the European Prospective Investigation into Cancer and Nutrition (EPIC) study. Br J Nutr. 2013;110:1500-11.

163. Di Renzo L, Carraro A, Minella D, Botta R, Contessa C, Sartor C, lacopino AM, De Lorenzo A. Nutrient Analysis Critical Control Point (NACCP): hazelnut as a prototype of nutrigenomic study. Food Nutr Sci. 2014;5:79-88

164. Di Renzo L, Merra G, Botta R, Gualtieri P, Manzo A, Perrone MA, Mazza M, Cascapera S, De Lorenzo A. Post-prandial effects of hazelnut-enriched high fat meal on LDL oxidative status, oxidative and inflammatory gene expression of healthy subjects: a randomized trial. Eur Rev Med Pharmacol Sci. 2017;21(7):1610-26.
165. Papageorgiou N, Tousoulis D, Katsargyris A, Charakida M, Androulakis E, Siasos G, et al. Antioxidant treatment and endothelial dysfunction: is it time for flavonoids? Recent Pat Cardiovasc Drug Discov. 2013;8:81-92.

166. Ahsan H, Ahad A, lqbal J, Siddiqui WA. Pharmacological potential of tocotrienols: a review. Nutr Metab. 2014:11:52

167. Wu SJ, Liu PL, Ng LT. Tocotrienol-rich fraction of palm oil exhibits anti-inflammatory property by suppressing the expression of inflammatory mediators in human monocytic cells. Mol Nutr Food Res. 2008:52:921-9.

168. de Mello VD, Kolehmainen M, Schwab U, Mager U, Laaksonen DE, Pulkkinen $L$, et al. Effect of weight loss on cytokine messenger RNA expression in peripheral blood mononuclear cells of obese subjects with the metabolic syndrome. Metabolism. 2008;57:192-9.

169. Yücesan FB, Orem A, Kural BV, Orem C, Turan I. Hazelnut consumption decreases the susceptibility of LDL to oxidation, plasma oxidized LDL level and increases the ratio of large/small LDL in normolipidemic healthy subjects. Anadolu Kardiyol Derg. 2010;10:28-35.

170. Sahibzada HA, Khurshid Z, Khan RS, Naseem M, Siddique KM, Mali M, Zafar MS. Salivary IL-8, IL-6 and TNF-a as potential diagnostic biomarkers for oral cancer. Diagnostics. 2017;7(2):21.

171. MaY, Ren Y, Dai ZJ, Wu CJ, Ji YH, Xu J. IL-6, IL-8 and TNF-a levels correlate with disease stage in breast cancer patients. Adv Clin Exp Med. 2017;26(3):421-6.

172. Di Renzo L, Bigioni M, Del Gobbo V, Premrov MG, Barbini U, Di Lorenzo N, De Lorenzo A. Interleukin-1 (IL-1) receptor antagonist gene polymorphism in normal weight obese syndrome: relationship to body composition and IL-1 alpha and beta plasma levels. Pharmacol Res. 2007;55(2):131-8

173. Di Renzo L, Sarlo F, Petramala L, lacopino L, Monteleone G, Colica C, De Lorenzo A. Association between - 308 G/A TNF-a polymorphism and appendicular skeletal muscle mass index as a marker of sarcopenia in normal weight obese syndrome. Dis Markers. 2013;35(6):615-23.

174. Di Renzo L, Bianchi A, Saraceno R, Calabrese V, Cornelius C, lacopino L, Chimenti S, De Lorenzo A. 174G/C IL-6 gene promoter polymorphism predicts therapeutic response to TNF-a blockers. Pharmacogenet Genom. 2012;22(2):134-42.

175. Jiang Q, Yin X, Lill MA, Danielson ML, Freiser H, Huang J. Long-chain carboxy-chromanols, metabolites of vitamin $\mathrm{E}$, are potent inhibitors of cyclooxygenases. Proc Natl Acad Sci USA. 2008;105:20464-9.

176. Nesaretnam K, Meganathan P. Tocotrienols: inflammation and cancer. Ann N Y Acad Sci. 2011;1229:18-22.

177. Hsieh TC, Wu JM. Suppression of cell proliferation and gene expression by combinatorial synergy of EGCG, resveratrol and gamma-tocotrienol in estrogen receptor-positive MCF-7 breast cancer cells. Int J Oncol. 2008;33:851-9.

178. Gecit I, Eryılmaz R, Kavak S, Meral I, Demir H, Pirinççi N, Güneş M, Taken $K$. The prolidase activity, oxidative stress, and nitric oxide levels of bladder tissues with or without tumor in patients with bladder cancer. J Membr Biol. 2017. https://doi.org/10.1007/s00232-017-9971-0.

179. Ilavarasi K, Kiruthiga PV, Pandian SK, Devi KP. Hydroxytyrosol, the phenolic compound of olive oil protects human PBMC against oxidative stress and DNA damage mediated by 2,3,7,8-TCDD. Chemosphere. 2011;84(7):888-93.

180. Colica C, Di Renzo L, Trombetta D, Smeriglio A, Bernardini S, Cioccoloni G, Costa de Miranda R, Gualtieri P, Sinibaldi Salimei P, De Lorenzo A. antioxidant effects of a hydroxytyrosol-based pharmaceutical formulation on body composition, metabolic state, and gene expression: a randomized double-blinded, placebo-controlled crossover trial. Oxid Med Cell Longev. 2017;2017:24.

181. Bhandari J, Muhammad B, Thapa P, Shrestha BG. Study of phytochemical, anti-microbial, anti-oxidant, and anti-cancer properties of Allium wallichii. BMC Complement Altern Med. 2017;17(1):102

182. Shukla Y, Singh R. Resveratrol and cellular mechanisms of cancer prevention. Ann N Y Acad Sci. 2011:1215:1-8.

183. Kraft TE, Parisotto D, Schempp C, Efferth T. Fighting cancer with red wine? Molecular mechanisms of resveratrol. Crit Rev Food Sci Nutr. 2009;49:782-99.

184. Milner JA. Molecular targets for bioactive food components. J Nutr. 2004;134:2492-8.

185. Algra AM, Rothwell PM. Effect of regular aspirin on long-term cancer incidence and metastasis: a systematic comparison of evidence 
from observational studies to versus randomized trials. Lancet. 2012;379:1602-12.

186. Parisi O, Puoci F, Restuccia D, Farina G, lemma F, Picci N. Polyphenols and their formulations: different strategies to overcome the drawbacks associated with their poor stability and bioavailability. Polyphenols Hum Health Dis. 2014;4:29-45.

187. Gatuillat G, Balasse E, Joseph-Pietras D, Morjani H, Madoulet C. Resveratrol induces cell-cycle disruption and apoptosis in chemoresistant B16 melanoma. J Cell Biochem. 2010;110:893-902.

188. Di Renzo L, Marsella LT, Carraro A, Valente R, Gualtieri P, Gratteri S, Tomasi D, Gaiotti F, De Lorenzo A. Changes in LDL oxidative status and oxidative and inflammatory gene expression after red wine intake in healthy people: a randomized trial. Mediators Inflamm. 2015;2015:317-48.

189. Jang M, Cai L, Udeani GO, Slowing KV, Thomas CF, Beecher CW, Fong $H H$, Farnsworth NR, Kinghorn AD, Mehta RG, Moon RC, Pezzuto JM. Cancer chemopreventive activity of resveratrol, a natural product derived from grapes. Science. 1997;275(5297):218-20.

190. Kundu JK, Surh YJ. Cancer chemopreventive and therapeutic potential of resveratrol: mechanistic perspectives. Cancer Lett. 2008;269(2):243-61.

191. Yamamoto H, Schoonjans K, Auwerx J. Sirtuin functions in health and disease. Mol Endocrinol. 2007;21(8):1745-55.

192. Borra MT, Smith BC, Denu JM. Mechanism of human SIRT1 activation by resveratrol. J Biol Chem. 2005;280(17):17187-95.

193. Finkel T, Deng CX, Mostoslavsky R. Recent progress in the biology and physiology of sirtuins. Nature. 2009;460(7255):587-91.

194. Di Renzo L, Carraro A, Valente R, lacopino L, Colica C, De Lorenzo A. Intake of red wine in different meals modulates oxidized LDL level, oxidative and inflammatory gene expression in healthy people: a randomized crossover trial. Oxid Med Cell Longev. 2014;2014:6813-8.

195. Magrone T, Panaro MA, Jirillo E, Covelli V. Molecular effects elicited in vitro by red wine on human healthy peripheral blood mononuclear cells: potential therapeutical application of polyphenols to diet-related chronic diseases. Curr Pharm Des. 2008;14:2758-66.

196. Dayem AA, Choi HY, Yang G-M, Kim K, Saha SK, Cho S-G. The anti-cancer effect of polyphenols against breast cancer and cancer stem cells: molecular mechanisms. Nutrients. 2016;8:581.

197. Kawaguchi K, Matsumoto T, Kumazawa Y. Effects of antioxidant polyphenols on TNF-alpha-related diseases. Curr Top Med Chem. 2011;11:1767-79.

198. Marzulli G, Magreone T, Kawaguchi K, Kumazawa Y, Jirillo E. Fermented grape marc (FGM): immunomodulating properties and its potential exploitation in the treatment of neurodegenerative diseases. Curr Pharm Des. 2012;18:43-50.

199. Kanaya N, Adams I, Takasaki A, Chen S. Whole blueberry powder inhibits metastasis of triple negative breast cancer in a xenograft mouse model through modulation of inflammatory cytokines. Nutr Cancer. 2014;66:242-8.

200. Bachmeier BE, Mohrenz IV, Mirisola V, Schleicher E, Romeo F, Hohneke C, Jochum M, Nerlich AG, Pfeffer U. Curcumin downregulates the inflammatory cytokines CXCL1 and-2 in breast cancer cells via NFkB. Carcinogenesis. 2008;29:779-89.

201. Singh BN, Shankar S, Srivastava RK. Green tea catechin, epigallocatechin-3-gallate (EGCG): mechanisms, perspectives and clinical applications. Biochem Pharmacol. 2011:82:1807-21.

202. Monteiro R, Calhau C, Pinheiro-Silva S, Guerreiro S, Gartner F, Azevedo I, Soares R. Xanthohumol inhibits inflammatory factor production and angiogenesis in breast cancer xenografts. J Cell Biochem. 2008;104:1699-707.

203. Tsao R, Li H. Antioxidant properties in vitro and in vivo: realistic assessments of efficacy of plant extracts. CAB Rev. 2012;7:9.

204. Mishra P, Kale R, Kar A. Chemoprevention of mammary tumorigenesis and chemomodulation of the antioxidative enzymes and peroxidative damage in prepubertal Spraque Dawley rats by Biochanin A. Mol Cell Biochem. 2008;312:1-9.

205. Singh B, Shoulson R, Chatterjee A, Ronghe A, Bhat NK, Dim DC, Bhat HK. Resveratrol inhibits estrogen-induced breast carcinogenesis through induction of NRF2-mediated protective pathways. Carcinogenesis. 2014;35:1872-80
206. Chen B, Zhang Y, Wang Y, Rao J, Jiang X, Xu Z. Curcumin inhibits proliferation of breast cancer cells through Nrf2-mediated downregulation of Fen1 expression. J Steroid Biochem Mol Biol. 2014;45:2045-51.

207. Ullah MF, Ahmad A, Zubair H, Kan HY, Wang Z, Sarkar FH, Hadi SM. Soy isoflavone genistein induces cell death in breast cancer cells through mobilization of endogenous copper ions and generation of reactive oxygen species. Mol Nutr Food Res. 2011;55:553-9.

208. Singh DV, Agarwal S, Singh P, Godbole MM, Misra K. Curcumin conjugates induce apoptosis via a mitochondrial dependent pathway in MCF-7 and MDA-MB-231 cell lines. Asian Pac J Cancer Prev. 2013;14:5797-804.

209. Braicu C, Pilecki V, Balacescu O, Irimie A, Berindan Neagoe I. The relationship between biological activities and structure of flavan-3-ols. Int J Mol Sci. 2011;12:9342-53.

210. Chou CC, Yang JS, Lu HF, Ip SW, Lo C, Wu CC, Lin JP, Tang NY, Chung JG, Chou MJ. Quercetin-mediated cell cycle arrest and apoptosis involving activation of a caspase cascade through the mitochondrial pathway in human breast cancer MCF-7 cells. Arch Pharm Res. 2010;33:1181-91.

211. Chien SY, Wu YC, Chung JG, Yang JS, Lu HF, Tsou MF, Wood W, Kuo SJ, Chen DR. Quercetin-induced apoptosis acts through mitochondrial and caspase-3-dependent pathways in human breast cancer MDA-MB-231 cells. Hum Exp Toxicol. 2009;28:493-503.

212. Seo HS, Ku JM, Choi HS, Woo JK, Jang BH, Go H, Shin YC, Ko SG. Apigenin induces caspase-dependent apoptosis by inhibiting signal transducer and activator of transcription 3 signaling in HER2-overexpressing SKBR3 breast cancer cells. Mol Med Rep. 2015;12:2977-84.

213. Thangapazham RI, Passi N, Maheshwari RK. Green tea polyphenol and epigallocatechin gallate induce apoptosis and inhibit invasion in human breast cancer cells. Cancer Biol Ther. 2007;6:2977-84.

214. Sakamoto T, Horiguchi H, Oguma E, Kayama F. Effects of diverse dietary phytoestrogens on cell growth, cell cycle and apoptosis in estrogenpositive breast cancer cells. J Nutr Biochem. 2010;21:856-64.

215. Chen J, Duan Y, Zhang X, Ye Y, Ge B, Chen J. Genistein induces apoptosis by the inactivation of IGF-1R/p-Akt signaling pathway in MCF-7 human breast cancer cells. Food Funct. 2015;6:995-1000.

216. Yang PM, Tseng HH, Peng CW, Chen WS, Chiu SJ. Dietary flavonoid fisetin targets caspase-3-deficient human breast cancer MCF-7 cells by induction of caspase-7-associated apoptosis and inhibition of autophagy. Int J Oncol. 2012;40:469.

217. Schiavano GF, De Santi M, Brandi G, Fanelli M, Bucchini A, Giamperi L, Giomaro G. Inhibition of cancer cell proliferation and in vitro tumorigenesis by a new red apple cultivar. PLoS ONE. 2015;10:1-17.

218. Jin $Y$, Hong Y, Park CY, Hong Y. Molecular interactions of autophagy with the immune system and cancer. Int J Mol Sci. 2017;18(8):1694.

219. Miki H, Uehara N, Kimura A, Sasaki T, Yuri T, Yoshizawa K, Tsubura A. Resveratrol induces apoptosis via ros-triggered autophagy in human colon cancer cells. Int J Oncol. 2012:40:1020-8.

220. Trincheri NF, Follo C, Nicotra C, Peracchio C, Castino R, Isidoro C. Resveratrol-induced apoptosis depends on the lipid kinase activity of vps34 and on the formation of autophagolysosome. Carcinogenesis. 2008:29:381-9.

221. Wang K, Liu R, Li J, Mao J, Lei Y, Wu J, Zeng J, Zhang T, Wu H, Chen L. Quercetin induces protective autophagy in gastric cancer cells: involvement of Akt-mTOR-and hypoxia-induced factor 1 alpha-mediated signaling. Autophagy. 2011;7:966-78.

222. Klappan AK, Hones S, Mylonas I, Bruning A. Proteasome inhibition by quercetin triggers macroautophagy and blocks motor activity. Histochem Cell Biol. 2012;137:25-36.

223. Christian F, Anthony DF, Vadrevu S, Riddell T, Day JP, McLeod R, Adams DR, Baillie GS, Houslay MD. P62 (SQSTM1) and cyclic amp phosphodiesterase-4A4 (PDE4A4) locate to a novel, reversible protein aggregate with links to autophagy and proteasome degradation pathways. Cell Signal. 2010;22:1576-96.

224. Lee YJ, Kim NY, Suh YA, Lee C. Involvement of ROS in curcumin-induced autophagic cell death. Khorean J Physiol Pharmacol. 2011;15:1-7.

225. Jia YL, Li J, Qin ZH, Liang ZQ. Autophagic and apoptotic mechanisms of curcumin-induced death in K562 cells. J Asian Natl Prod Res. 2009;11:918-28. 